Chapman University

Chapman University Digital Commons

6-2013

\title{
The Status Costs Of Subordinate Cultural Capital: At-Home Fathers' Collective Pursuit Of Cultural Legitimacy Through Capitalizing Consumption Practices
}

\author{
Gokcen Coskuner-Balli \\ Chapman University, balli@chapman.edu
}

Craig J. Thompson

University of Wisconsin

Follow this and additional works at: https://digitalcommons.chapman.edu/business_articles

Part of the Behavioral Economics Commons

\section{Recommended Citation}

Coskuner-Balli, Gokcen, and Craig J. Thompson. "The status costs of subordinate cultural capital: athome fathers' collective pursuit of cultural legitimacy through capitalizing consumption practices." Journal of Consumer Research 40.1 (2013): 19-41.

DOI:10.1086/668640

This Article is brought to you for free and open access by the Business at Chapman University Digital Commons. It has been accepted for inclusion in Business Faculty Articles and Research by an authorized administrator of Chapman University Digital Commons. For more information, please contact laughtin@chapman.edu. 


\section{The Status Costs Of Subordinate Cultural Capital: At-Home Fathers' Collective Pursuit Of Cultural Legitimacy Through Capitalizing Consumption Practices}

\section{Comments}

This article was originally published in Journal of Consumer Research, volume 40, issue 1, in 2013. DOI: $10.1086 / 668640$

\section{Copyright}

University of Chicago Press 


\title{
The Status Costs of Subordinate Cultural Capital: At-Home Fathers' Collective Pursuit of Cultural Legitimacy through Capitalizing Consumption Practices
}

\author{
GOKCEN COSKUNER-BALLI \\ CRAIG J. THOMPSON
}

\begin{abstract}
Consumer researchers have primarily conceptualized cultural capital either as an endowed stock of resources that tend to reproduce socioeconomic hierarchies among consumer collectivities or as constellations of knowledge and skill that consumers acquire by making identity investments in a given consumption field. These studies, however, have given scant attention to the theoretical distinction between dominant and subordinate forms of cultural capital, with the latter affording comparatively lower conversion rates for economic, social, and symbolic capital. To redress this oversight, this article presents a multimethod investigation of middle-class men who are performing the emergent gender role of at-home fatherhood. Our analysis profiles and theoretically elaborates upon a set of capitalizing consumption practices through which at-home fathers seek to enhance the conversion rates of their acquisitions of domesticated (and subordinate) cultural capital and to build greater cultural legitimacy for their marginalized gender identity.
\end{abstract}

In Bourdieu's world, all [social actors] are capital holders and investors seeking profits. (Swartz 1997)

$\mathrm{P}$ ierre Bourdieu's multifaceted concept of cultural capital has become a theoretical touchstone for consumer researchers investigating the social-cultural structuring of consumption (Allen 2002; Arsel and Bean 2012; Arsel and Thompson 2011; Bernthal, Crockett, and Rose 2005; Henry 2005; Holt 1998; Illouz and John 2003; Kates 2002; Schulz 2006; Üstüner and Holt 2007, 2010). These studies have developed along two analytically distinct trajectories; the first explores the ways in which consumers' respective levels of cultural capital systematically influence their aesthetic

Gokcen Coskuner-Balli (balli@chapman.edu) is assistant professor of marketing and research affiliate of the Economic Science Institute at the Argyros School of Business and Economics, Chapman University, Orange, CA, 92868. Craig J. Thompson (cthompson@bus.wisc.edu) is the Gilbert and Helen Churchill Professor of Marketing, University of WisconsinMadison, Madison, WI 53706.

Mary Frances Luce served as editor and Søren Askegaard served as associate editor for this article.

Electronically published November 7, 2012 tastes, consumption choices, and lifestyle patterns (e.g., Allen 2002; Arsel and Bean 2012; Holt 1998). The second calls attention to the forms of cultural capital that are produced, distributed, and deployed within consumption communities (or subcultures of consumption; Kates 2002; Martin, Schouten, and McAlexander 2006; Muñiz and Schau 2005). We argue that consequential theoretical relationships among consumers' cultural capital investments, collective identity projects, and status hierarchies among consumption fields have fallen, largely unstudied, in the conceptual space between these two research streams. To explain the theoretical contributions that can accrue from excavating these interstitial issues, we must first give closer consideration to the core tenets that have guided these prior studies.

The first aforementioned research stream directly builds upon Bourdieu's axiom that consumers' primary socialization-via family upbringing, formative peer groups, and formal educational experiences-endows them with stocks of generalized cultural capital that are manifested as habituated tendencies and generative predispositions (Bourdieu 1984; Bourdieu and Wacquant 1992). This family of studies characteristically presents comparisons between consumers who are classified as having higher or lower levels of generalized cultural capital. While recognizing that consumers 
participate in a variety of distinct social and consumption fields, these studies subsume such contextual nuances within a broader consideration of how consumers' levels of generalized cultural capital-as expressed through their consumption practices, aesthetic tastes, and choice preferences -tend to reproduce socioeconomically based status distinctions (Allen 2002; Bernthal et al. 2005; Henry 2005; Holt 1998; Schulz 2006; Üstüner and Holt 2007, 2010).

The second theoretical orientation follows in a path pioneered by Sarah Thornton's (1996) concept of subcultural capital. Taking a cue from the Birmingham School's studies of working-class subcultures (Hebdige 1979; McRobbie 2000; Willis 1981), Thornton challenged Bourdieu's theoretical assertion that the status value of a given species of cultural capital was set by the values, interests, and tastes of dominant social class factions. Her ethnographically grounded counterargument held that social groups who occupy lower positions in the socioeconomic hierarchy could create their own systems of status and ascribe positional value to subcultural capital that would typically not have currency in elite social fields.

Thornton's (1996) influential propositions have been further developed by consumer researchers investigating the forms of field-dependent capital that consumers acquire through identity investments in consumption communities (Arsel and Bean 2012; Arsel and Thompson 2011; Kates 2002; Martin et al. 2006; Muñiz and Schau 2005; Schau, Muñiz, and Arnould 2009). Much like Thornton's subcultural capital (but not as exclusively tied to working-class and youth-oriented countercultural practices), a given species of field-dependent cultural capital is situated within the sociocultural and material networks that constitute a given consumption community (Celsi, Rose, and Leigh 1993; Kjeldgaard and Askegaard 2006; O'Guinn and Muñiz 2005; Schouten and McAlexander 1995). These studies have shown that consumers' acquisition and use of field-dependent cultural capital plays a central role in generating collective identifications and organizing in-group social hierarchies (Kates 2002; Schau et al. 2009) and intrafield status competitions (Arsel and Bean 2012; Arsel and Thompson 2011; Üstüner and Holt 2010).

An understudied tangency between these research streams is that status hierarchies also exist among different consumptions fields. For example, yachting tends to carry a higher degree of social prestige than bowling, and those who tend to belong to yachting clubs are also likely to possess higher levels of economic capital — and have routine interactions with those in higher status social and occupational positions - than consumers whose leisure preferences gravitate toward more readily affordable and lower status options, such as bowling. Thus, the yachting field affords field-dependent cultural capital that more readily converts into social capital among those in positions of authority and power; economic capital (e.g., such as that attained through information about highly remunerative investment and career opportunities); and symbolic capital (e.g., prestige, respect, social influence, and authority in matters of taste).
The socioeconomic stratification among consumption fields raises questions about the interrelationships between consumers' acquisitions of field-dependent capital and broader status hierarchies - particularly those grounded in class and gender distinctions - that culturally and ideologically frame such identity investments. We explore these questions through a cultural analysis of the consumption practices and identity narratives of at-home fathers. Men investing in this emergent identity position are forgoing the culturally dominant masculine role of being the family's economic provider to instead assume household and primary caregiver responsibilities that have been conventionally associated with femininity and motherhood.

In the following sections, we first review and reconceptualize prior consumer research on generalized and fielddependent cultural capital from a perspective that highlights the different conversion rates offered by dominant and subordinate forms of cultural capital. Next, we specify the research gaps that will be redressed by our study of at-home fathers. Turning to our research context, we discuss some of the major sociohistoric conditions that have rendered domesticity as both a cultural province of femininity and a devalued form of cultural capital. We then analyze the capitalizing consumption practices which at-home fathers have incorporated into their collectively shared identity goals of increasing the conversion rate of their acquisitions of domestic cultural capital and attaining greater cultural legitimacy for their alternative performances of fatherhood and masculinity.

\section{REMAPPING THE STRUCTURAL CHARACTERISTICS OF CONSUMER DISTINCTIONS BASED ON CULTURAL CAPITAL}

While eschewing the rational actor assumptions of human capital theory (see Swartz 1997), Bourdieu (1986) argues that when consumers accumulate new forms of cultural capital, they are making a de facto investment in particular constellations of skills, knowledge, and cultivated aptitudes. The status value of these acquired stocks of cultural capital lies in their exchangeability, or conversion rate, for additional forms of cultural capital (e.g., credentials, knowledge, and skills), social capital (e.g., advantageous social connections), economic capital (e.g., occupational opportunities, etc.), and symbolic capital (social recognition, prestige, authority, respect, legitimacy, and other laudatory demarcations) that contribute to one's overall socioeconomic standing (Bourdieu 1986). Importantly, the conversion rate afforded by a given species of cultural capital is a function of the social fields in which it is deployed and the underlying relations of socioeconomic advantage or disadvantage that structure the distribution of cultural, social, and economic resources among social fields.

From this standpoint, different forms of cultural capital can be remapped onto a dimension of dominant versus subordinate, which cuts across the generalized versus field-de- 
pendent distinction. Dominant cultural capital is acquired (and leveraged) in social fields where those holding higher positions in the socioeconomic hierarchy tend to compete for resources that sustain or enhance their social standing (Lamont and Lareau 1988), such as elite private schools, prestigious professional associations, exclusive neighborhoods, cosmopolitan social clubs, and occupational spheres linked to the economic and political power centers of the global economy (Boltanski and Chiapello 2005). Conversely, subordinate forms of cultural capital are possessed by those who hold lower positions in the socioeconomic hierarchy and serve to demarcate their socially marginalized status - even though these symbolic markers may provide ingroup legitimacy for their bearers (Bourdieu and Passeron 1977; Carter 2003; Willis 1981). Since subordinate forms of cultural capital typically circulate in marginalized social fields, they also have comparatively low conversion rates for those forms of capital that confer status in the upper echelons of the socioeconomic hierarchy.

A corollary to Bourdieu's arguments about social reproduction is that consumers tend to organize their daily routines, and hence make identity investments, in social fields that are largely compatible with their socialized predispositions (and endowments of generalized cultural capital). As an illustration of these conditions of homology (Bourdieu and Wacquant 1992), imagine a high cultural capital (HCC) consumer whose daily routine unfolds across a constellation of social spaces that are geared to his/her habituated tastes, preferences, and interests, such as a cultural creative occupational field, cosmopolitan leisure fields, and a gentrified neighborhood replete with ethnic restaurants, upscale boutiques, and arts-oriented third spaces. In such cases, the various forms of field-dependent capital that an HCC consumer accrues through his/her recreational, leisure, and shopping/dining practices should serve to reinforce predispositions deriving from his/her endowments of generalized cultural capital. These homologous forms of field-dependent capital would also likely provide status value across these status congruent fields (i.e., a consumer's knowledge about the latest natural food trend would likely be a topic of shared interests among those in her/his Bikram yoga class).

However, Bourdieu also acknowledged that significant sociocultural disruptions-such as those precipitated by colonial occupation (Bourdieu 1977) — could create conditions of heterology in which individuals must compete for status in social fields that are structurally incompatible with their socialized aptitudes and generative dispositions (Bourdieu and Wacquant 1992). Although not always an explicit point of theoretical interests, consumer researchers have similarly shown that consumers' lives are frequently marked by heterologies, due to postmodern transformations of status quo socioeconomic and ideological relations, forces of economic and cultural globalization, and the ever-expanding array of diversified identity resources that can be accessed through the marketplace (Holt 2002; Kjeldgaard and Askegaard 2006; Schau, Gilly, and Wolfinbarger 2009; Üstüner and Holt 2007; Üstüner and Thompson 2012).
Figure 1 represents some of the key structural relationships that can arise between consumers' class-based socialization and field-dependent forms of cultural capital. The vertical axis represents the conventional continuum between HCC and low cultural capital (LCC) consumers, which implies that their primary socialization has been shaped by consequential differences among the socioeconomic and cultural milieus in which they were respectively raised (see Bourdieu 1986; Bourdieu and Wacquant 1992). The horizontal axis indicates that social fields, including consumption-oriented ones, are also positioned in a status hierarchy. Higher status fields are oriented around dominant forms of cultural capital whereas lower status fields are sites where subordinate forms of cultural capital have significant currency. Homologous fields are structurally compatible with consumers' higher or lower cultural capital endowments and afford fits-like-a-glove experiences (Allen 2002). In contrast, heterologous fields are structurally incompatible with consumers' habituated predispositions and are likely to spark feelings of unease, insecurity, or a reflexive awareness of the social incongruities in play.

The upper left quadrant in figure 1 encompasses situations where consumers with higher cultural capital backgrounds are cultivating dominant forms of field-dependent cultural capital and playing the requisite status games using their appropriately habituated skills. Bourdieu's (1984) canonical writings on the reproduction of elite distinction directly correspond to this type of homology. In these cases, HCC consumers gravitate toward higher status social fields which are linking nodes in the circuits of socioeconomic power and whose forms of field-dependent cultural capital are ideologically represented in the broader culture as rarefied tastes. Holt $(1997,337)$ addresses this quadrant when analyzing the cosmopolitan lifestyles led by higher cultural capital professionals. Allen's (2002) study of the sociological influences that predispose young adults hailing from HCC backgrounds to have strong elective affinities for elite, liberal arts colleges further demonstrates how such homologies operate in the education field. In a parallel fashion, Bardhi, Eckhardt, and Arnould $(2012,513)$ show that the habituated predispositions of global nomads, whom they characterize "as an elite mobile professional group," create strong predilections for the culturally omnivorous tastes and cosmopolitan lifestyle practices that generally distinguish higher cultural capital consumers from lower cultural capital ones.

The lower right quadrant in figure 1 represents an alternative form of homology in which LCC consumers gravitate toward consumption fields that occupy a lower or peripheral status in the broader socioeconomic hierarchy, as exemplified by Thornton (1996). In these cases, consumers leverage the structural compatibilities between their LCC predispositions and the homologous consumption field to valorize forms of field-dependent capital that are commonly marginalized in broader socioeconomic status hierarchies. Although not explicitly discussing cultural capital, Schouten and McAlexander's (1995) ethnographic description of how working-class Harley riders' symbolically differentiate them- 
FIGURE 1

CONSUMER STATUS GAMES UNDER CONDITIONS OF HOMOLOGY AND HETEROLOGY

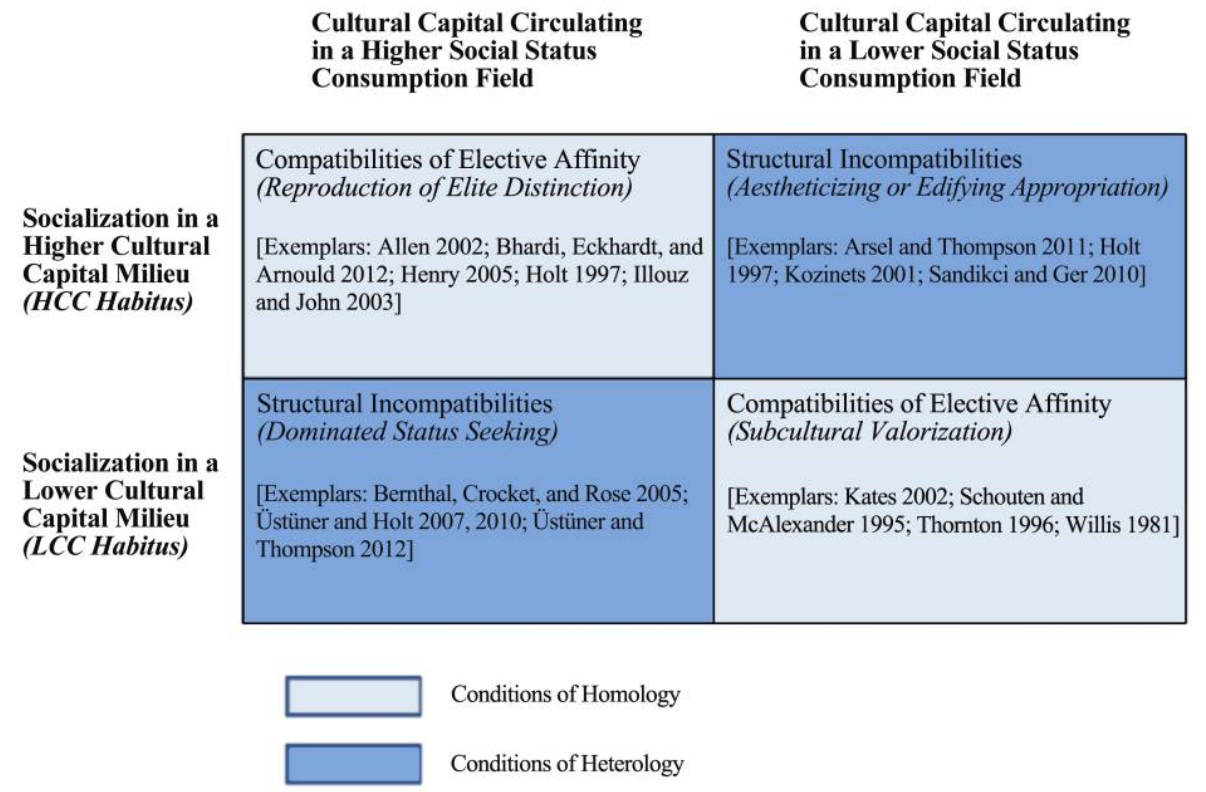

NOTE.- $-\mathrm{HCC}=$ high cultural capital; LCC $=$ low cultural capital.

selves from professional Harley riders — whom they denigrate as RUBs (rich urban bikers) and yuppie poseurs-suggests that these blue-collar consumers are building field-dependent capital in a class homologous subgroup or tribe within the broader Harley-Davidson brand community.

Prior to Thornton (1996) and Schouten and McAlexander (1995), Paul Willis's (1981) Learning to Labor documented how the social backgrounds of younger British working-class males channeled this social group toward dead-end (and rapidly disappearing) factory jobs by engendering strong preferences toward practical, hands-on knowledge; an idealization of manual labor; antipathy toward intellectual pursuits; and strong desires to be accepted as peers by older workingclass men (in the fields of the shop floor and the pub). Almost 25 years later, Allen (2002) found that similar working-class predispositions shaped LCC consumers' choices for postsecondary education in ways that also tended to sustain their economic marginalization. Whereas HCC homologies facilitate the reproduction of elite distinction (and socioeconomic advantage), the practices of subcultural valorization manifest in LCC homologies can all too easily contribute to the reproduction of socioeconomic disadvantage.

Kates (2002) provides another socioculturally nuanced analysis of LCC homologies. His ethnography of a gay, urban subculture reveals that the social distinctions forged through displays of subcultural capital can also express op- position toward alienating heterosexist norms. Kates (2002) further shows that the acquisition of gay subcultural capital enables consumers with LCC backgrounds to become proficient at aestheticizing and ironizing consumption practices that are normally indicative of HCC consumption styles, thereby demonstrating that class-based predispositions can be reconfigured through intersections of gender socialization, gender ideologies, and identity politics (also see Reay 2004).

Turning to conditions of heterology, the lower left quadrant represents structural mismatches that arise when consumers socialized in a lower cultural capital milieu seek to acquire field-dependent capital in a higher status social field. These types of structural incompatibilities often result in dominated status seeking whereby LCC consumers compete for resources in status games favoring those possessing $\mathrm{HCC}$ backgrounds. This dynamic is elucidated by Üstüner and Holt's (2007) analysis of young adult women, born and raised in Turkish squatters, who are attempting to play status games that have been naturalized in the lifestyles of middleclass consumers. However, these squatter women lack the requisite levels of economic, social, and cultural capital and their identity aspirations are eventually shattered by these intractable class barriers. Üstüner and Holt $(2010,51)$ subsequently investigate a less tragic form of dominated status seeking pursued by HCC Turkish consumers and conclude that 'HCCs' dogged pursuit of the Western Lifestyle myth 
leads many of them to the vexing conclusion that they will never truly succeed. ... Their perception that they are unable to enact Western lifestyle in a natural taken-forgranted way forces them to acknowledge that they actually occupy a rung on the global class ladder below the Western middle class whom they want so much to view as peers."

Üstüner and Thompson (2012), highlight another variation upon dominated status seeking whose sociological consequences fall between the shattered identity projects suffered by young adult squatter women and the feelings of cultural inadequacy and insecurity that plague an otherwise affluent, HCC segment of Turkish society. Üstüner and Thompson (2012) report on the market-mediated processes that enable Turkish men, hailing from impoverished, LCC backgrounds, to build specific forms of middle-class capital. Through their cultural capital acquisitions - and their marketplace performances that provide sufficient economic capital to purchase various material symbols of middle-class standing-these underclass Turkish men avoid the profound disappointments experienced by squatter women pursuing a similar goal. However, their lack of formal education, respected family names, childhood histories in affluent neighborhoods, and other shortfalls in their stocks of social and cultural capital still pose significant structural barriers to being accepted as legitimate members of middle-class society by their higher status clientele.

The heterologies represented in the upper right quadrant most directly correspond to our research context and motivating research questions. Under this condition, higher cultural capital consumers make identity investments in lower status consumption fields and subordinate forms of cultural capital. Such heterologies can be created when consumers integrate subordinate cultural capital into their established lifestyle routines and status games, thereby refashioning these acquisitions into new markers of social distinction; or, second, when consumers more fully and completely vest their identities in the lower status field and subsequently face the prospect of status loss and cultural marginalization. Whereas the consumer research literature has primarily addressed the former case, with an emphasis on consumers' practices of aesthetic and/or edifying appropriation, our analysis focuses on this latter scenario.

Highlighting the status value of aesthetic appropriation, Holt (1997) argues that RUBs (a class faction of the HarleyDavidson brand community) are appropriating the hypermasculine design elements and rebellious cultural associations of Harley-Davidson motorcycles into their own HCC status games (also see Holt 2004). Arsel and Thompson's (2011) study of middle-class indie music consumerswhose aesthetic tastes, fashion styles, and other forms of field-dependent cultural capital have been culturally (and problematically) branded as hipster-also indirectly address practices of aesthetic appropriation. One of the semiotic markers of hipster style is the ironic appropriation of quintessentially working-class consumption objects, such as trucker hats, PBR beer, plaid shirts, courier bags, and cowboy boots. Much like RUBs, hipsters aesthetically transform these working- class symbols into forms of objectified cultural capital that forge distinctions to other factions of middle-class youth culture.

Kozinets's (2001) analysis of how Star Trek fans come to accept, as a badge of honor, the social stigma attached to Trek fandom can also be used to illustrate a case of edifying appropriation. In regard to this stigma, Jenkins (1992) and Jenkins and Tulloch (1995) argue that it follows from the denigrating cultural view of science fiction fans as being preternaturally obsessed with a trivial, escapist form of lowbrow culture. However, Star Trek fans, at least the more creative and technically inclined, have been cultural pioneers in the use of computer technologies and Internet communications networks as well as being ardent cultural producers of fan-generated fiction, music, and video (skills now widely celebrated as practices of consumer cocreation; see Jenkins 1992; Kozinets 2001). As Jenkins and Tulloch (1995, 4) further discuss, the recognition in the broader news and entertainment media that "MIT students, NASA engineers, and other [high] technical people find the program compelling" has precipitated a more sympathetic cultural portrayal of Star Trek fandom. Seen in this light, the dominant forms of cultural capital (scientific and technological knowledge) that this higher status segment of Star Trek fans has brought to the consumption field has resulted in an edifying appropriation of its field-dependent capital.

Sandikci and Ger (2010) document a socioculturally and politically charged manifestation of aesthetic appropriation enacted by professional class metropolitan Turkish women. Assisted by a nexus of marketplace and institutional forces, this formerly secular social group has transformed the stigmatized Islamist practice of veiling into a fashionable and more socially acceptable consumer choice. As Sandikci and Ger (2010) explain, the gradual destigmatization of tesettür fashion entails a sociocultural and political re-embedding of a sartorial practice that had formerly been associated with the impoverished and less educated rural sector of Turkish society. This rural collectivity had been ideologically marginalized by Turkey's cultural and political elites for being radically out of step with the nation's dominant agenda of secularization and economic modernization (also see Eligür 2010).

Through a complex series of sociocultural and political disruptions, however, field-dependent cultural capital linked to political Islam has become a status-conferring source of distinction among particular factions of Turkey's middle and upper classes (Eligür 2010; Gülalp 2001). From the perspective offered by our framework, Sandikci and Ger (2010) are highlighting how tesettür women use their generalized cultural capital-garnered through their middle-class upbringing, formal education, and, most of all, lifelong immersion in the sphere of secularized and Westernized consumer culture-to remake the formerly stodgy and unflattering tesettür into a more urbane, appealing, and hybridized fashion style; aestheticizing practices that draw legitimacy from the rising sociocultural stature of political Islam as a 
countervailing ideology to the secularizing Kemalist political legacy.

While having clear tangencies to Sandikci and Ger (2010), our study explicitly focuses on the question of what happens when consumers make significant investments in subordinate forms of cultural capital and then must confront the limits and status costs posed by its relatively low conversion rate in the broader socioeconomic hierarchy. We analyze the consumption practices and use of marketplace resources undertaken by middle-class men who have abdicated their former breadwinner role in favor of managing the household and acting as primary caregivers for their children. In response to their experiences of status loss and social stigma, at-home fathers are striving to forge a collective identity, based upon their shared experiences of marginalization, and to build cultural legitimacy for their unconventional performance of masculinity and fatherhood. Toward this end, they engage in capitalizing consumption practices that aim to enhance the conversion rates of their acquisitions of subordinate cultural capital associated with child care, cooking, shopping, cleaning, laundry, and other forms of domestic labor.

As widely noted by sociologists, historians, and gender studies scholars, knowledge and skills related to the domestic realm have been culturally coded as a duty or obligation of motherhood, ever since the so-called separation of spheres doctrine attained its high degree of socioeconomic institutionalization (Cowan 1983; Hochschild 2003; Strasser 1982). Although cultural shifts toward more egalitarian gender ideals have altered some of the normative mandates and expectations about men's and women's roles in the domestic sphere, numerous studies have shown that women have, for the most part, maintained the primary responsibilities for managing the household (Braun et al. 2008; Davis, Greenstein, and Marks 2007). Importantly, housework and forms of cultural capital situated in the domestic field remain economically undervalued (Folbre and Yoon 2008; Zick and Bryant 2008), making it an exemplary case of subordinate cultural capital.

\section{HOW DOMESTIC CULTURAL CAPITAL BECAME GENDERED (AND SUBORDINATED)}

Historians mark the Industrial Revolution and the separation of the home and the public sphere as an important turning point in the cultural construction of masculinity and fatherhood (Coltrane 1996; Kimmel 1997). According to historian John Gillis (1996), the development of the market economy in the nineteenth century set in motion sociocultural forces that restructured family life in terms of a bifurcated gender order. Fatherhood increasingly became linked to the public sphere of paid work, whereas motherhood, particularly in middle-class households, became closely associated with the privatized sphere of domestic life (Griswold 1993; Kimmel 1997; LaRossa 1997). Throughout the twentieth century, various experts in disciplines such as psychology and home economics further promulgated the ideological belief that women were more naturally suited to the tasks of domestic management and child care than men (Cowan 1983; Strasser 1982). Conversely, fathers' participation in the domestic sphere has been normatively defined by practices of breadwinning, domestic discipline, outdoor recreation, protection, and mentoring about the responsibilities of adulthood (particularly for their sons), all of which stand as distinctive complements to the nurturing norms manifest in cultural ideals of middle-class motherhood and femininity (Cross 2008; Gillis 1996; Kimmel 1997; Weiss 2000).

The separation of spheres doctrine initially led to a sanctification of (middle-class) homemakers by culturally framing the domestic realm and (the corresponding practices of traditional motherhood) as a revitalizing space in which the nuclear family could gain moral, spiritual, and emotional sustenance (Matthews 1987). However, the sequestering of domesticity from the market economy created an ideological condition in which the economic value of these diversified activities could be all too easily subsumed (and hidden) within the routinized and feminized responsibilities of homemaking (Jackson 1992). As Victorian era reservations over the moral taxation posed by the market economy faded and a host of technological advances contributed to a general deskilling of housework, this socioeconomic devaluation became a cultural reality.

Although contemporary social conditions have been dramatically altered by second-wave feminism and the increased presence of women in the workforce, the separation of spheres has given rise to entrenched symbolic categories, gendered practices, and normative expectations that continue to shape the identities of middle-class men and women. Numerous studies have shown that married women-across the social class spectrum-still perform the bulk of domestic labor (Casper and Bianchi 2002; Giele 2008; Mannino and Deutsch 2007), a social inertia that attests to the enduring linkage of domestic cultural capital to cultural models of femininity and motherhood. Even among relatively egalitarian families where men participate more fully in housework, women tend to retain responsibilities for organizing and managing the tasks; to undertake more repetitive and mundane tasks such as cleaning, ironing, and laundry; and to remain more engaged in the key nurturing tasks that fall under the general cultural rubric of emotional labor (Breen and Cooke 2005; Davis et al. 2007; Reay 2004).

In contrast, men are more likely to understand themselves as being domestic helpers and to perform more stereotypically masculine tasks such as mowing the lawn or playing with children (Coltrane 2000; Deutsch 2000). Middle-class fathers are also expected to be more committed to their jobs than mothers, such that men who take paternity leave or reduce their work hours to be more involved in the domestic sphere run the risk of being marginalized for lacking career dedication and drive (Coltrane 1996; Coltrane and Adams 2008; Pleck 1993). Gender theorists have further documented that men often confront social stigmas, identity crises, and marital discord when they deviate from the nor- 
mative role of being the household's primary wage earner (Coltrane 1996; Commuri and Gentry 2005; La Rossa 1988). For example, Commuri and Gentry (2005) report that couples find it necessary to jointly construct a number of compensatory strategies to minimize the identity threats that men experience when their wives are the primary wage earners for the family.

Our findings suggest that at-home fathers have formed, as part of their cultural capital repertoire, a collective and reflexive understanding of the ideological incongruities between their emergent social identity, prevailing gender norms, and their primary socialization in gender-based social practices, ideals, expectations, and status hierarchies linked to the breadwinner model of masculinity. Their capitalizing consumption practices are fundamentally intertwined with the ideological goal of attaining greater cultural legitimacy for their unconventional performances of fatherhood and masculinity.

\section{METHOD}

A multimethod and longitudinal data-collection approach, which included in-depth interviews, a netnography of athome father blogs, and field ethnography at playgroups and other at-home father outings were adopted for the study. A modified phenomenological interview technique was designed to elicit descriptions of participants' experiences of their sociocultural circumstances (Thompson, Locander, and Pollio 1989). At-home fathers were recruited and interviewed by the first author through two different local playgroups in Orange County, California, via Internet postings, and at the annual "At-Home Dads Convention" organized by the National At-Home Dad Network, Daddyshome, Inc. Table 1 provides demographic profiles of the at-home fathers interviewed for the study.

The recent US Census Bureau estimate in 2011 suggests that there are 176,000 at-home fathers in the United States. While a comparatively small social category, the ranks of at-home fathers have been rising rapidly and are now more than three times larger than a decade ago (Shaver 2007). At-home fathers' generational cohort is variously characterized as late baby boom or the thirteenth generation, with most falling in the age range of mid-30s to early 40s (Rochen et al. 2008; Smith 2009). According to a national study, over $90 \%$ of the men who self-identify as at-home fathers are white middle-class college graduates (Rochlen et al. 2008).

Our 17 participants largely fit this profile, with the exception of two who did not have college degrees (pseudonyms Lyle and Rob) and one who fell outside the typical age range (pseudonym Scott). Fifteen of our 17 participants voluntarily withdrew from the paid workforce, with eight of those also having wives whose respective careers offered higher earning potentials than their own. Among the involuntary cases, Lyle was unable to find employment after relocating to a new city (following his wife's career path) and Scott became an at-home father in part to better manage stress-related health concerns that he believed had been exacerbated by work pressures.

While each of our participants had unique personal stories about their identity journeys, these at-home fathers confronted a remarkably similar set of social perceptions and identity struggles. Their understanding of these conditions tended to draw from a collectively shared system of gender ideologies, and they embraced a common set of strategies for capitalizing their acquisitions of domesticated cultural capital. Accordingly, our analysis highlights these collectively shared properties, which accords with our driving theoretical questions as well as broader calls for Consumer Culture Theory analyses that map out the sociocultural and ideological conditions which function as the conditions of possibility for emic/phenomenological narratives (see Askegaard and Linnet 2012; Thompson 1997).

Depending on participants' schedules and availability, the first author met with each participant multiple times and at different locations. All interviews were recorded and tran-

TABLE 1

PARTICIPANTS' DEMOGRAPHIC PROFILE

\begin{tabular}{llllll}
\hline \hline Informant & Age & \multicolumn{2}{c}{ Education } & Former full-time occupation & \multicolumn{1}{c}{ Wife's occupation } \\
\hline Adam & 33 & BA & Magazine rep. & Real estate manager & Boy (4 and 3 mo.), girl (2) \\
Andy & 45 & BS & Stock trader & Account manager & Girl (3), boy (1, 5) \\
Brian & 36 & BS & Financial consultant & Divorced & Boy (3) \\
Daniel & 35 & BA & Graphic designer & Accountant & Girl (7), boy (5), boy (3) \\
Derek & 40 & MA & Sound designer & Biochemist & Girl (6) \\
Eric & 38 & BS & Marketing manager & Nurse & Girl (3), boy (5) \\
Jeff & 41 & AA & Video producer & HR manager & Boy (4 and 9 mo.) \\
Joe & 47 & MS & Social worker & Schoolteacher & Boy (1.5) \\
Kenneth & 42 & BA & Insurance broker & Health care manager & Boy (11) \\
Lyle & 36 & High school & Window cleaner & Retail manager & Girl (2 and 6 mo.) \\
Mike & 38 & BS & Web designer & Rabbi & Girl (7), boy (3) \\
Nick & 33 & MA & Screenwriter & Sales manager & Girl (2 and 6 mo.) \\
Richard & 38 & BA & Account planner & PhD student & Boy (7), girl (6 mo.) \\
Rob & 36 & High school & HR manager & Medical student & Girl (2) \\
Scott & 54 & BA & Engineer & Bank teller & Boy (20), boy (17) \\
Tom & 40 & BS & Disc jockey & Sales manager & Girl (3), boy (1) \\
Vince & 44 & BA & Archeologist & Yoga instructor & Girl (8), boy (10) \\
\hline
\end{tabular}


scribed verbatim for textual analysis. The interviews began with grand-tour questions (McCracken 1988) regarding each participant's family background, work history, and personal interests. Interview questions focused on participants' daily routines and household responsibilities, social networks, child care practices, relationships with their wives and children, and their experiences and feelings toward the brands, products, stores, and services they used. In these interviews, participants offered spontaneous and often extensive reflections on various cultural expectations, images, and ideals of masculinity and fatherhood that they deemed relevant (both in facilitative and problematic ways) to their personal identities and to those of other at-home fathers.

Ethnographic observation across multiple field sites provided another key data set regarding how at-home fathers' social experiences unfolded in everyday and liminal contexts. In terms of everyday settings, several participants were accompanied on grocery shopping trips and other kinds of provisional shopping excursions to various retailers such as PetSmart, Target, and IKEA. The primary liminal sites were two playgroup sites where weekly meetings of at-home fathers took place, an indoor children's playground franchise (Jump'n Jammin'), and the annual at-home fathers national convention. On several occasions, observations of participants, who live fairly close to Disneyland, were conducted when they retreated to this iconic playscape with their children as a break from the regular routine.

The third major data-collection method of the study was netnography (Kozinets 2010). For a total period of 18 months, online blogs of at-home fathers were analyzed to identify some of the public discourse that they use to define their collective identities relative to traditional breadwinner dads. After an initial screening of the 150 blogs for relevance and posting frequency, we identified 67 blogs-based on richness and relevancy - for detailed analysis, generating 2,208 pages of single-spaced text and images. These blogs helped us identify everyday problems and challenges that galvanized at-home fathers' sense of collective identity. Furthermore, the netnographic data offered a source of triangulation that enabled us to assess if the themes that emerged from the phenomenological interviews and ethnographic observations had relevance and resonance across the broader community of at-home fathers.

We adopted a hermeneutic approach to analyze this multifaceted data set that developed through a series of part-towhole iterations (Thompson 1997). Over the course of the interpretive cycle, we developed provisional understandings of key emic motifs and underlying sociocultural patterns that were in turn challenged and modified with each iterative turn. As we shifted to a more etic standpoint, we situated our participants' emic narratives in their broader sociocultural context, with an emergent emphasis on the relationships between their unconventional gender identities; their collective quest for social legitimacy; their investments in a subordinated form of cultural capital; and their collective efforts to increase the conversion rate of these investments.

\section{CAPITALIZING CONSUMPTION PRACTICES OF AT-HOME FATHERS}

At-home fathers' capitalizing consumption practices are embedded in a particular configuration of sociocultural meanings, economic conditions, and gender ideologies (see fig. 2). Accordingly, we will provide an overview of three key contextualizing factors that have framed these at-home fathers' practices of capitalizing consumption: ideological shifts that set the cultural stage for the emergence of the at-home father identity; the prior stocks of capital that at-home fathers strategically use to facilitate their acquisition of domesticated cultural capital; and the ensuing identity tensions that provided a sociocultural impetus for their capitalizing consumption practices.

\section{The Quest for a Legitimating Ideology of Masculine Domesticity}

Second-wave feminist and countercultural criticisms of many traditional masculinity ideals-particularly those related to emotional stoicism, careerism, and authoritarian models of fatherhood-have contributed to the erosion of conventional gender boundaries and also helped to institutionalize the normative edict that fathers should be more involved in the day-to-day care of children (Bolzendahl and Myers 2004; Coltrane 1996; Cross 2008; Deutsch 2000). Despite these sociocultural shifts, norms and practices emanating from the separation of spheres doctrine continue to exert a normative influence on cultural perceptions of gender-appropriate behavior for mothers and fathers. Brescoll and Uhlmann (2005) investigated the perceptions of adult Americans toward unconventional models of parenthood. They found that affective responses and perceptions of parental competence toward at-home fathers were considerably lower than for either stay-at-home mothers or fathers holding full-time jobs outside the home. Another source of ideological inertia is that middle-class masculine gender norms continue to link normatively appropriate masculine identities to career achievement and financial wherewithal (Holt and Thompson 2004).

While the performative codes of breadwinner masculinity have broadened to include more playful, caring, and sensitive orientations-the so-called new male archetype (Cross 2008; MacKinnon 2003; Mallan 2002) - these gender-norm shifts have added a degree of cultural complexity to the breadwinner model, rather than displace it per se (Connell and Messerschmidt 2005; Hatfield 2010). This confluence of ideological influences is reflected in our participants' identity narratives. They readily acknowledge that their unconventional lifestyle choices reflect desires to have a closer relationship with their children than they had with their career-oriented fathers, as well as a related idea that their experiences of at-home parenting provide emotional rewards that cannot be attained through the pursuit of career and material success:

Jack: My father was always working, very busy. He was an engineer, but he also had several other jobs, so one thing I 
FIGURE 2

\section{CAPITALIZING CONSUMPTION PRACTICES OF AT-HOME FATHERS}

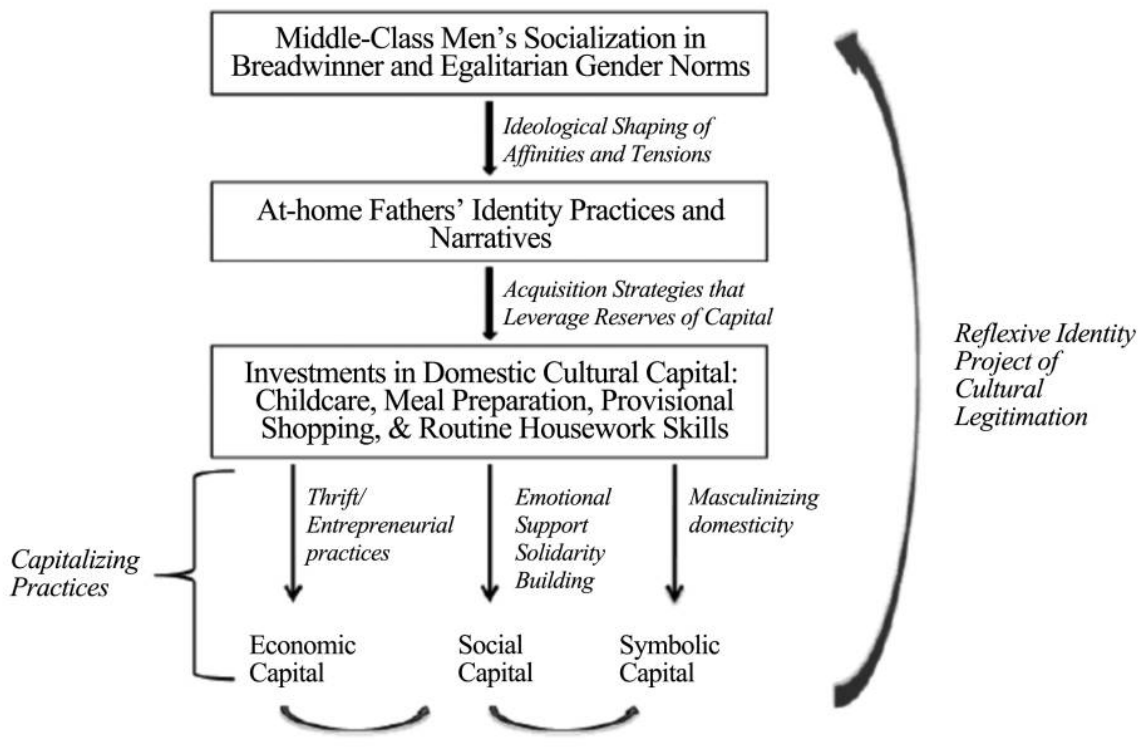

was able to do here that my dad didn't do is spend a more significant amount of time with him [his son]. Although I try to find my esteem in work, I have not always been successful in doing that, and I am at a point now I don't really care necessarily if I do find my esteem in work. I find it more with this guy. You know, it has given me a purpose outside myself to live.

While having ready ideological rationales for their lifestyle choices, these men's habituated norms of breadwinner masculinity are not so easily abandoned. When reflecting on their at-home father lifestyle in fuller detail, these men also discuss their pangs of guilt and doubt over not having a career outside the home and their anxieties over not contributing to the household's income stream:

Eric: I felt like that was the right decision but there is still that part of you that still says you ought to be making so much money or you ought to be out there in the work world, or you got to be contributing. You know, however you want to put it. There is that pull, and at first I really felt that pull and maybe a little bit of guilt. You are feeling, okay, I am taking care of a child, while somebody else, other men, are out there earning incomes, so there is some guilt involved in that. And then there is also the stigma of being an at-home father, which is kind of an unusual thing. You know, it is not what people are used to. You introduce yourself, I am an athome father, and a lot of times the reaction you get is, "Oh, that's nice." And you don't know what to say, especially to other men who are working. . . . You kind of feel like a fish out of water.
Once immersed in this new role, these men face a nexus of domestic tasks-child care, provisional shopping, daily meal preparation, routine housework-for which they had very limited prior experience. They draw upon their social capital to attain additional domestic knowledge and they use their economic capital (often begrudgingly, owing to their own lack of an external income stream) to buy resources (books, tools, services, and classes) that can facilitate their transition to this new role. Importantly, they are keenly aware of cultivating new domestic skills and altering their orientations toward shopping:

Daniel: It took me a while to learn how to go shopping because I would go shopping and come home and she would be pissed when she saw how much I spent, because I hadn't really gotten it yet, how to look for prices and learn how to do it. And to really shop I would just get whatever I wanted and throw that in the basket and some of that and you end up spending a tremendous amount of money and having nothing to show for it. . . . I went with her a few times and also as I learned to cook. When she used to do it I was always blown away with how long it would take her to go shopping. She would be gone for a long time and I would think, man, what takes so long? When I go shopping I' $m$ in and out of there, you know, but to really go shopping and be costconscious and get what you need for the menu for the week or whatever you're going to be making it takes some time. You really do need to think.

The emergence of mass media domestic doyens, such as Martha Stewart and Paula Dean, has precipitated a cultural 
revalorization of homemaking practices, albeit of a highly aestheticized variety. However, these media icons have also served to reinforce traditional associations between domesticity and femininity and have had little impact on the major sources of delegitimation reported by at-home fathers: social deviance from breadwinner norms and the concomitant feminization of their identities (i.e., the Mr. Mom stereotype). Accordingly, at-home fathers report that they are routinely confronted by disparaging social biases, as exemplified in the following interview vignette:

Eric: There is a bias that dads work, and moms may or may not work. I have been in situations occasionally like I'll be out with 2 of my friends and they work they are full time workers, engineers in fact, and they might make a belittling comment about a stay home mom you know, I'll be standing there wait a second, I am a stay home dad what do they think of me? I think we were at a birthday party and one of the moms she had spent a lot of time on a really nice cake for the child, she has decorated it and everything and one of the dads said oh, it must really nice to be a stay home mom and have all that time on your hands. You know they were kind of belittling what she had done. And I just thought if you are belittling stay home moms it doesn't say much about stay home dads.

These historically established gender ideologies render athome fathers' investments in domesticated cultural capital as delegitimating, status liabilities. Humphreys $(2010,492)$ discusses two dimensions of cultural legitimacy that are particularly relevant to the collective identity project being pursued by at-home fathers: "normative legitimacy is the degree to which the practice is perceived to be congruent with dominant norms and values, irrespective of legal status" and "cognitive legitimacy is the degree to which the practice is 'taken for granted,' the ease with which it can be categorized and understood according to existing cognitive schemas and cultural frameworks." At-home fathers' unconventional performances of masculinity and fatherhood currently do not possess normative legitimacy due to their divergence from dominant breadwinner gender norms. Their narratives further indicate that the collective identity of at-home fathers does not simply lack cognitive legitimacy. Instead, it exhibits a form of cognitive illegitimacy whereby their deviance from dominant gender expectations is readily interpreted through pejorative cultural frameworks, such as the Mr. Mom stereotype or incompetent caregiver presumptions.

While having made willing identity investments in a subordinate form of cultural capital, our participants' habituated predispositions as members of a dominant gender and class group make it difficult for them to accept being placed in a marginalized social position. Accordingly, at-home fathers undertake a series of capitalizing practices that seek to enhance the status value of their domesticated cultural capital by converting it into more valued forms of economic, social, and symbolic capital.

\section{Conversions to Economic Capital}

At-home fathers use a combination of thrift and entrepreneurial practices to convert their domestic cultural capital into economic capital. In lieu of a steady income stream, at-home fathers embrace the idea that they are providing economic value to the household by being thrifty shoppers who scour the marketplace for good deals whether for toys or daily groceries:

Rob: Yesterday I was at the children orchard right by the gym. I stopped by there I was looking for a kitchen cause I want to get Josie a kitchen. You know, you go to any other store, they want, you know, 100 to 200 dollars for them. We don't want to spend that kind of money right now but, um, children's orchard, they buy and sell things so they you can get them at a really good price.

PenMan (Internet pseudonym): I have to get to the store quick to get more than one loaf of bread. . . . I would brave the horde because this is what my life has somehow become. Chasing food sales with a vengeance. I am the Van Helsing of grocery shopping. And I have to get at least 3 loaves of bread. It's the good bread, not that high quality cardboard that I usually buy for the kids and me. The stuff I buy is usually $\$ 1.38$. That's right, I know exactly how much a loaf of bread costs. The good stuff runs me almost 2 bucks. However, this weekend, and this weekend only, there is a sale on the good bread for 99 cents a loaf. . . . As I jump the curb and leave the road behind me, I ponder how I came to this point. When saving 39 cents on a loaf of bread was a matter of great importance. Does it really matter enough to run down the poor cows in the field that I am now driving in? Somehow, to me, it does. I buy roughly 8 loaves of bread a month. That makes a lot of peanut butter and jelly sandwiches, another staple of ours. That means that if I can buy 8 loaves at 99 cents, stack the extras in the freezer, then I save a total of $\$ 3.12$ a month. I am running over orphans for 3 bucks. I'm not proud man and yet, I do not change my tactics. (October 18,2010 , rebeldad.com)

Miller (1998) argues that female homemakers interpret their practices of thrifty shopping (and the paradoxical idea of spending as saving) as a source of supplemental value they can allocate to family members as tokens of care (also see Bardhi and Arnould 2005; Thompson 1996). In the case of at-home fathers, the meanings of thrift emerge from a different configuration of gender ideologies. The homemakers in Miller's (1998) ethnography perform their role in ways that mesh with their prior gender socialization and reproduce traditional cultural associations among motherhood, shopping, cooking, and expressions of maternal devotion. For at-home fathers, their practices of thrift are situated in an ideological claim that they are prioritizing their responsibilities as fathers rather than as pursuers of career success and its materialistic trappings:

Brian: I don't see myself ever going back to that [his highpressured career]. I have been kind of humbled, I guess. There 
is no way I would spend $\$ 2,000$ on a suit for the rest of my life. I am driving a Toyota now, you know, instead of a Mercedes. There is when you have something that you really care about, the other stuff is window dressing. It is not important now. So, I can't say I matured. Maybe I de-matured. It is more like he is an excuse for me to play now, go to the park and play have a good time and go to the slide. I mean, if I were wearing a $\$ 2,000$ suit and $\$ 1,200$ cashmere jacket, I wouldn't slide down the slide. I'd try to protect my stupid Armani shoes rather than. . . . [Laughs.] It is not important anymore. I guess at a certain time, probably a year out of college, status was important to me. When you have a child, it doesn't become your priority anymore. So I guess I've evolved to a point where I am just having fun with my son now.

Echoing sentiments expressed by other at-home fathers we interviewed, Brian has constructed an affirming selfportrayal: he could easily possess these symbols of status and success but he no longer needs to vest his identity in such superficial indicants of self-worth. This reflexive identity narrative appropriates the cultural ideal of authenticity and its concomitant rendering of consumerism as a sphere of superficial and conformist pursuits (Chidester 2005; Holt 2002).

Our participants routinely contrast their at-home father identity to their former, more career-oriented lifestyles, with a strong emphasis on what they no longer consume, such as haute cuisine restaurants, expensive business suits, and other conventional status symbols. While these lifestyle changes most immediately reflect an economic imperative to reduce expenditures, at-home fathers interpret their downscaled consumption patterns as signs that they have reoriented lives around more substantial and rewarding interests and activities. Through this identity narrative, at-home fathers venerate their deviation from breadwinner norms as liberation from the restrictive demands of status chasing and careerism while making masculine status claims that invoke hallowed cultural ideals of authenticity, inner-directedness, devotion to family, and moral virtue.

At-home fathers also see themselves as supporting their wives' pursuit of success and status in the corporate sphere and view their thrifty orientations as freeing up economic resources that their wives can convert into forms of cultural capital that are valued in the occupational sphere:

Kenneth: The frugalness part of it is I'm always in shorts and a polo shirt. Very rarely am I in this. [He is wearing khaki pants and a shirt.] I happen to be in this because I had to go to Jake's [son] meeting this morning. Jake always says, "Well, dad, why are you dressing like a man today?" [Laughs.] Because I'm always in shorts, a shirt, and tennis shoes. . . . But I push Pam up the corporate ladder. . . . I'll go look at Victoria's Secret, Lane Bryant, Banana Republic, Macy's, Bloomingdale's, and look for different outfitspower suits, spring outfits, cocktail dresses, coats, those type of things that make a statement.

This particular conversion strategy has some historical parallels to what historians of fashion characterize as the great masculine renunciation. During the mid- and late nineteenth century (in the United Kingdom and United States) successful entrepreneurs and affluent industrialists, almost in mass, abandoned the sartorial extravagances that had been a hallmark of aristocratic distinction. Instead, they adopted an ethos of understated, plain dress (which aligned their personal styles with the Protestant work ethic animating the spirit of capitalism) while brandishing their wives in expensive, quick to stylistic obsolescence, and generally impractical garments and fashion accoutrements (Wilson 2003). Like their historical predecessors, at-home fathers are defining their identities through an overt disavowal of masculine status games premised on the stylistic vagaries of the fashion cycle, which in this contemporary case entails designer business suits and high end brands. Whereas fin de siècle industrialists conspicuously displayed their own career success and economic wherewithal through their wives' ostentatious wardrobes, at-home fathers now play the conventional dress-forsuccess status game, in a vicarious manner, through their wives' careers. Accordingly, they interpret their wives' rising professional status as both reflections and affirmations of the economic contributions to the household that accrue from their acquisitions of domesticated cultural capital.

At-home fathers' thrifty sensibility is further distinguished by a rebel-trickster (Holt and Thompson 2004) subtext that treats the marketplace as a network of free or very low cost recreational facilities and ludic playscapes (Sherry et al. 2004). At an at-home father convention, one attendee enthusiastically talked about his routine excursions to Home Depot: "I go to Home Depot every day. When it was first opened, my son and I were there first thing in the morning. To this day, I go and browse the aisles. 'What can you tell me about this tool, and this one?"' (said mimicking a question asked to a sales associate; author field notes). In a similar spirit, Adam discusses how he learned to minimize the costs of his daily parenting excursions through his playful appropriation of retail spaces:

Adam: Where I live there's a Pet Smart. Right next to it is Babies R Us and right next to it is a Sports Chalet and when I have to kill an hour or two we go into each of those stores and they love it. I don't even buy anything, but it's like going to the zoo.

\section{Interviewer: What do you guys do in Pet Smart?}

Adam: We just look at the animals. They have like the doggies that are there for the day so the kids love to look at the dogs and they love turtles. They've got snakes in there. It's kind of like going to the zoo for free. I've gotten a lot better. When I first had Mac I just thought I had to get him really involved so I would take him to museums and the aquarium and I found we were just spending a lot of money for something that I wanted to do and now I take him to all this free stuff.

Interviewer: What do they like about the sporting goods store? 
Adam: That one is a quiet one and quiet stores are really nice. It's really big and what's neat is when you first enter they have little tricycles for kids. So actually what my kids do is they get on the tricycles and they ride them all around the store. So I just follow them around and we just ride their tricycles. We take the store's bikes and ride them around the store and nobody seems to care. . . . My son loves golf and he loves to go to the golf area. He just likes to go back to the golf and swing the clubs and so it's great. It's almost like you can introduce him to all these new sports and in Pet Smart you introduce them to all these new animals, and I like that.

At-home fathers' thrift-oriented conversions are complemented by entrepreneurial practices that aim to generate revenue streams from their domesticated cultural capital. At-home fathers' collective identity is marked by a key ideological tension between their desires to escape the allconsuming, hypercompetitive labor market (and more conventional patriarchal status games) and their habituated sense of responsibility to be economic providers for their families. For the at-home fathers in this study, entrepreneurial practices are a salient means to assuage some of the contradictions (and corresponding feelings of guilt and diminished self-esteem) that arise between their full-time commitments to the domestic sphere and their lingering emotional ties to breadwinner norms, even though their actual earnings may be modest at best.

Consider Kenneth, an ex-nurse and doula, who has taken on many entrepreneurial initiatives since he has become an at-home father 12 years ago. Kenneth works as a part-time insurance broker, offers swimming classes in his backyard pool, and rents out rooms of his house to exchange students and adults with disabilities. For Kenneth, these entrepreneurial initiatives allow him to feel that he is not shirking his breadwinner responsibilities while also allaying worries that his decision to leave the paid workforce might compromise his son's future life opportunities:

Kenneth: I had to be thrifty, frugal, and still keep my entrepreneurship skills and business skills to be able to make this work.

Interviewer: Interesting. Can you tell me more about the entrepreneurship skills?

Kenneth: Before Jake was born, I hosted an exchange student. Then after Jake was born I kept it up. You know when you add the nurturing part of it [to entrepreneurship] and the structure of the house.

Interviewer: When you have the older people and the exchange students, how does it all work?

Kenneth: Depending on their age I can put two in a room. Also in my garage I have IKEA furniture, twin beds so this area right here becomes a bedroom. I'll put the IKEA beds here at night and this area is shut down by 9 o'clock unless you have to go get water or what have you, but the bathrooms are back here and so nobody is disturbing anybody's sleep, and then when they take off for school after they have breakfast I break this down and put it back. This living room will never be the same. I get compensated for these exchange students. So by the time Jake reaches college, he will have a lot of savings.

Stories about at-home fathers' entrepreneurial initiatives and successes have a broad appeal within the broader collectivity of at-home fathers. One example is The Stay-atHome Dad Handbook (Baylies and Toonkel 2004), a popular resource within the community. It offers numerous inspirational stories of fathers who began successful businesses after they took on the primary caregiver role. These recurrent stories of at-home fathers' entrepreneurial acumen contribute key meanings to the identity myth (Holt 2004) that these men seek to propagate and materially establish in the marketplace: by capitalizing on their creative ideas and handson parenting knowledge, men can escape the confinements of the corporate world, build a fraternal community where men help other men, control their own financial destinies, and be involved fathers at the same time.

At-home fathers are particularly appreciative of entrepreneurial innovations that produce marketplace resources that are tailored to their sociocultural positions. Consider Rob, who recounts a consumption tale that echoed throughout other interviews and in blogs: the quest to find appropriately masculine props for the enactment of their unconventional gender roles and thereby avoid Mr. Mom clichés:

Rob: You know there is an at-home father in Santa Monica that kind of designs these [pointing to his bag] diaper bags and kind of makes them manly. He is making a lot of money now. I heard about it, the website, once and my wife researched the guy. . . . She got it [the bag] for me. . . . I just don't want to carry a pink bag with large flowers on it. [Laughs.]

At-home fathers' entrepreneurial practices also advance their collective goal of attaining cultural legitimacy through marketplace recognition of their identity position. This motif is nicely illustrated (and culturally diffused) by the origin story of DadGear, a brand founded by two transitioning athome fathers, Scott Shoemaker and John Brosseau:

It all started in late 2003 over a plate of nachos. We, the two founders, were commiserating together over our corporate jobs when the conversation migrated to our newfound passion . . . our babies. We both had just entered the new world of fatherhood and were keenly focused on all the "gear" we acquired to care for our children-strollers, car seats, cribs, and of course . . . the diaper bag. We both were frustrated in our quest to find a diaper bag that inspired us. Neither of us wanted to carry mom's flowery diaper bag, but our search for something masculine and functional was futile. So, as dads are known to do, we decided to fix the problem and set out to design some dad gear.

We spent a year and a half developing ideas and countless prototypes. From the very beginning, we knew we wanted our gear to be synonymous with quality, style, and superior 
function. And, as we became more experienced fathers, we leveraged our knowledge to design helpful features that would make life easier for other parents out there. Finally, in spring 2005, DadGear ${ }^{\mathrm{TID}}$ was officially launched. (http:// www.dadgear.com/story.cfm)

In this origin story, two men, holding down respectable jobs, collaboratively altered their life priorities as their passion for parenting took hold. Rather than retreating into a completely private sphere, these men embarked on a new mission to solve a collective problem facing at-home fathers who must negotiate a maternally oriented marketplace. As an identity myth, the DadGear origin story also affirms that men can perform their at-home father roles in ways that are enterprising and socially consequential without having to conform to the norms of breadwinner masculinity. For athome fathers, such marketplace innovations are also celebrated as a kind of grassroots push toward marketplace recognition of their role as primary caregivers which could, in turn, imbue their collective identity with greater cultural legitimacy.

\section{Conversions to Social Capital}

Bourdieu $(1986,51)$ defines social capital as "the aggregate of the actual or potential resources which are linked to possession of a durable network of more or less institutionalized relationships of mutual acquaintance and recognition -or in other words, to membership in a group." Once this group identity is established, a variety of resources-information, material goods (via sharing, loans, and gifts), and social support-can flow through these social networks (Lin 2001; Mathwick, Wiertz, and de Ruyter 2008).

The formation of social capital is contingent upon forging a sense of collective identity (Lin 2001). Such mobilizing efforts can be sparked by the problems and challenges facing those embedded in a common set of socioeconomic conditions-such that their access to economic and cultural capital is improved by pooling and sharing their respective resources (Lin 2001) — or by shared cultural and aesthetic interests whose value can be amplified through collective participation in a consumption community (Schau et al. 2009). This first catalyst is exemplified by the solidarity building practices characteristic of working-class, ethnic enclaves, and politics-of-identity formations, such as the LGBT community (Lin 2001; Kates 2003). Here, membership in the collectivity is ideologically framed, not as a matter of personal choice and individual discretion, but as a morally binding struggle for socioeconomic fairness and greater voice in political processes. In contrast, consumers typically understand their investments in consumption communities as volitional choices, reflecting their avocational interests and values (Kozinets 2001; Muñiz and O'Guinn 2001).

In many respects, at-home fathers' collective identifications structurally resemble the value-expressive (and supportive) linkages characteristic of polit-brand communities (O’Guinn and Muñiz 2005). They interpret their collective identifications as goal-directed choices, rather than binding moral obligations, which they can alter at a later point in life. However, at-home fathers also express a more (gender) politicized understanding that they constitute a social group that has been unjustly stigmatized for its divergence from conventional masculine/fatherhood norms:

Derek: You know, walking into various parks with my daughter, there is definitely stigma when all these mothers are gathered and they all know each other and there I am with my daughter. And they are like "Hey, who are you?" And my daughter likes to meet people and she's very outgoing and because of that . . . I mean it's not a bad thing, but it scares some kids cause she'd just come right up to you and hug you even if she doesn't know you and some kids kind of back off from that. And so then with those kinds of relationships what happens is the mothers say, "Hey, can't you control your daughter?" or something like that and I'd be like "I don't really think I need to control my daughter." I think that she needs to learn personal space but I think she is pretty nice and welcoming she is not doing anything bad. But there seems like there is some kind of judgment values on dads.

Derek's narrative accords with Petroski and Edley's (2006) and Rochlen, McKelley, and Whittaker's (2010) survey-based findings that at-home fathers are routinely confronted by questions about their competence and trustworthiness as primary caregivers. However, at-home fathers' experiences of being treated as interlopers, or as parents of questionable competence, when taking their children to playgrounds, parks, and other conventional parenting spaces serve to reinforce their sense of sharing a marginalized collective identity. Such ostracizing encounters also provide compelling incentives for at-home fathers to convert their cultural capital (which includes empathetic identification with men in similar sociocultural circumstances) into social capital by forming at-home father playgroups. Through this social capital building practice, at-home fathers claim public parenting spaces as legitimate stages for performing their unconventional gender identity and reciprocally, their manifest displays of social capital help to buffer stigmatizing reactions.

At-home fathers' collective identifications and corresponding sense of phatic understanding (see Celsi et al. 1993) are also grounded in their common experiences of social isolation and feelings of personal stagnation:

Eric: You know, that just kind of started about four months ago when Mike called me and he said, "Eric, I am going insane, I need a dads' night out, we should plan it." And, um, you know, you get those days when you are with the kids just some days you are like you know "I can't take it anymore." I need to get in the adult world. I set up a date. A bunch of us went to Dave and Busters, which is a local kind of bar and game room kind of place combination. . . . We'll just do things once in a while, you know, to keep our friendships keep going. You know, leave the kids at home, do something fun just for the dads. 
Along with Dads' night outs and other planned respites from their domestic responsibilities, these men further allay their feelings of social isolation by engaging in social media interactions with other at-home fathers. These web-based forums such as rebeldad.com, fatherneed.com, and stayathomedad.org provide informational resources, social networking opportunities, and a means to exchange stories, ideas, and solutions to common problems. At-home father blogs contain rich information regarding the daily lives of at-home fathers, their relationships with their children, the brands and products they use in their everyday lives, and photographs and videos documenting their daily routines. Aside from instrumental and social benefits, at-home fathers' participation in these forums provides solidarity building reassurance that their everyday problems, anxieties, and gaps in domestic knowledge are not idiosyncratic failings but instead are collectively shared qualities of their emergent social identity.

McAlexander, Schouten, and Koenig (2002) report that social gatherings strengthen the social ties and feelings of collective identification among those in a consumption community by facilitating face-to-face interactions and the emotional immediacy of shared experiences and bonding rituals. In a manner consistent with this brandfest strategy (McAlexander and Schouten 1998), at-home fathers further cultivate social capital by organizing an annual convention where they can share their experiences and viewpoints. Since its inception in 1995, this yearly event has been organized by a group of volunteer at-home fathers who use online forums to poll other community members about what activities and sessions should be on the convention program. The convention also provides travel funds for at-home fathers who could not otherwise attend the event due to financial limitations.

In the liminal space of this social gathering, at-home fathers step back and reflect on the complexities and dilemmas related to performing a nontraditional gender role. In some cases, these exchanges function as venting rituals through which at-home fathers voice their collectively shared frustrations, such as the stigmatizing reactions they receive in the public sphere. For example, one dad recounted how a passenger on his plane ride to the conference called at-home fathers "a bunch of losers." Another dad told how he was often treated as a persona non grata when taking his children to public parks, lamenting that "moms would talk over me, as if I was not even there." The at-home fathers in attendance bonded over stories about the myriad disapproving and judgmental comments they received from their in-laws. Through these venting rituals, at-home fathers could also rhetorically claim the position of being the enlightened parties and share in identity-affirming proclamations that others (in-laws, moms, other men who are not at-home fathers) "just don't get it" (author field notes).

This convention also builds social solidarity through a fairly recurrent interaction ritual: men new to the at-home father identity describe how their abdication of the breadwinner role, and dependency upon their wives for financial support, had precipitated varying degrees of self-doubt and emotional distress. In response, more experienced at-home fathers offer comforting rationales such as pointing out that child care and household care made valuable economic contributions to their families, paralleling an argument that feminist advocates have long made with regard to women's domestic labor (Gimenez 1990). In the conference sessions, at-home fathers share advice and information regarding household products and other forms of domestic knowledge - such as how to style their daughters' hair — that have been culturally coded as feminine knowledge and largely foreign to their own gender socialization.

The at-home father convention is also a forum where these men can express frustrations over their lack of recognition by the commercial marketplace and discuss strategies for combating the prevailing marketing assumption that mothers are the primary caregivers (and shoppers for the household). From difficulties in finding an appropriately masculine diaper bag, to reading parental magazines that address the audience as mothers only, to changing diapers in public parks where men's restrooms lack baby care stations, athome fathers share a myriad of examples where they feel marginalized by media, advertising, and major manufacturers who offer few child care products designed for male caregivers:

A large part of my pre-stay-at-home existence was like focused on how I am going to avoid all the girly crap . . . a really good stroller, a diaper bag that you are going to be able to use a lot and not feel ashamed is not the right word but like stupid to walk around with. . . . I ended up getting a bag from Jack Spade, it is called dad's field bag. (Author field notes)

Note to baby-product makers: Alienating half of your potential market is not a right move for you (and frustrating for those of us out here trying to make the point that dads and moms are equally capable of parenting and buying stuff). (Rebel Dad, May 29, 2007, rebeldad.com)

More generally, at-home fathers' stories of being ignored or misunderstood by marketers and of scouring the marketplace for parenting products that are not overtly coded as feminine provide a highly resonant narrative of collective identity. From their standpoint, a lack of marketplace options attuned to their situations not only poses constraints upon their identity project but also signals that the broader culture has yet to confer the cultural recognition and legitimacy they seek.

\section{Seeking Symbolic Capital (the Quest for Cultural Legitimacy)}

From a Bourdieuian standpoint, our cohort of at-home fathers has been socialized into a system of cultural norms and expectations which are indicative of a higher status position in the social hierarchy formed by the intersection of class and gender. In keeping with their habituated dominant group predispositions, at-home fathers are unwilling 
to passively accept the marginalizing status quo or to embrace their identity stigma as a martyr-like badge of honor-in a manner akin to Kozinets's (2001) Star Trek devotees. Rather, they seek to elevate the status position of their collective identity in hopes that their decisions to become primary caregivers will eventually elicit respect and admiration, rather than ridicule and disparagement.

Each of the capitalizing practices described in the preceding sections constitute indirect means for attaining symbolic capital. By converting their domesticated cultural capital into economic and social capital, at-home fathers gain symbolic resources for reinscribing their collective identity in cultural meanings that can facilitate their collective quest for cultural legitimacy. However, at-home fathers also engage in capitalizing practices that more directly seek to enhance the status value of their investments in the domestic realm. These latter, more direct, capitalizing practices all serve the goal of masculinizing domesticity and, thereby, target a major source of cognitive illegitimacy that plagues their collective identity: the feminizing (and hence emasculating) associations conventionally invoked by their full-time commitment to the domestic realm. These masculinizing practices are (1) resituating their domestic responsibilities in the public sphere; (2) altering the cultural connotations of domesticity through an emphasis on technological acumen and DIY projects; and (3) outsourcing their responsibilities for meal preparation to the commercial marketplace, thereby dissociating their identities from connotations of domestic drudgery and maternal duty.

At-home fathers' first masculinizing practice, in the most pragmatic sense, strategically renders the public spaces of the marketplace, rather than private sphere of the home, as the natural stage for their playful performance of domesticity. Historically, women have often relied upon marketplace resources, particularly department stores, to resocialize domesticity (Leach 1984; Sparke 1995). In reflexive deference to this cultural association between retail spaces and feminine sociability, our at-home fathers shied away from using conventional shopping venues as a pretext for their public excursions. Rather, more ludic oriented outdoor spaces, such as parks, playgrounds, and their own backyards (a domesticated playspace) are far more central to at-home fathers' identities.

Drawing from the cultural codes that frame specific types of commercial spaces as ludic-oriented masculine preserves (Sherry et al. 2004), at-home fathers also gravitate toward theme parks and themed restaurants, where they can place a decidedly masculine stamp on their approach to child care, such as by interjecting a fraternal spirit into their outdoor excursions: "As we left Disneyland, we concluded our day with having another beer at Disney downtown area. Tom told me that having a second beer at the downtown area was a Disney routine to get his parking ticket validated as it costs $\$ 6$ per hour after the first hour. By the end of the hour, though, Tom and Andy decided to stay on for another beer" (author field notes).

At-home fathers take pride in letting their children take more risks in playground settings than they envision moms normally would. They further characterize themselves being more spontaneous and less bound by rigid routines than moms, which they see as generating more opportunities to have fun with their children. In playground settings, at-home fathers actively involve themselves in their children's play: a practice that they also believe sets them apart from mothers who they construe as being more likely to (guardedly) observe from the sidelines. For example, "at a Jump'n Jammin' (an indoor children's playground), mothers sat at the cafeteria section chatting and occasionally attending to their children while they played; the dads' group, on the other hand, went in the cannonball fire area and played with the children and also among themselves as they fired cannons at each other" (author field notes).

Cross (2008) posits that contemporary middle-class men (that is, those having boomer generation parents) have strong cultural predilections to avoid the responsibilities of adult masculinity by living a state of perpetual adolescence through their consumption interests (e.g., video gaming, provocative yet puerile men's magazines such FHM, and movies featuring man-boy characters such as Adam Sandler's Happy Gilmore). At-home fathers, however, are not fleeing from adult responsibilities through their playful personas. Rather, they have integrated a playful approach, and even moments of childlike exuberance, into the fulfillment of their caregiver role. Through these playful and public gender performances, at-home fathers construct themselves as fun loving and adventurous parents, who are not feminized by domestic responsibilities and who retain a quintessentially masculine, rebellious spirit (Holt and Thompson 2004).

At-home fathers also seek to masculinize their domesticated cultural capital by portraying themselves as adroit users of technology and as skillful DIY practitioners. In the former case, at-home fathers readily discuss how their willingness and capacity to use technological solutions transforms their family scheduling and housework tasks into less burdensome and even enjoyable aspects of their daily routine:

Joe: Things like digital cameras and like that I think are important um because you are talking about storing a lot of pictures and saving and backing them up because the stuff can get lost so I look at being a mom a bit different in that regard.

Interviewer: What do you mean?

Joe: Well, meaning I am just thinking of my wife, I think a good computer and a good digital camera is important being a parent, my wife might see not as important.

Daniel: I go back to the iPhone again [as his most essential parenting tool] because it's just so much you can do with that. It's got calendars where you save the events for school or whatever is coming up. Shopping, it's got the notes-I put notes into it. You can jot down things that you're shopping for that you need. It provides entertainment for the kids when 
need be and it's communication and information, just all the way around. . . . I have many alarms that tell me throughout the week different things to do, to take out the trash to when different schools schedules vary or it's my day to pick up the other kids.

By displaying technical prowess through activities such as digital photography and archiving family photos on image hosting websites such as Flickr (incidentally a very popular workshop topic at the at-home fathers' convention), at-home fathers leverage deep cultural associations between technology and masculine power and control (Cockburn 1985; Holt and Thompson 2004; Kendall 2000). Digital technologies have acquired specific ideological meanings in the postmillennial era that have a particular resonance for athome fathers. In particular, Dempsey (2009) notes a trend in media and advertisements to represent male users of hightech goods as mavericks who defy societal pressures to follow the crowd and, instead, pursue their self-directed, selfactualizing objectives: a salutary ideological construction that at-home fathers have incorporated into their quest for cultural legitimacy.

Similarly, at-home fathers characterize their DIY projects in terms that emphasize creativity and autotelic pleasure (Holt 1998). Hence, their narratives and social media tend to highlight DIY projects that provide entertaining or educational experiences for their children, such as building dollhouses, sandboxes, and other accoutrements of childhood play, rather than those directed toward general maintenance tasks (e.g., plumbing and car repairs):

Rob: Lately I have been looking up material to build a dollhouse bookshelf. I can buy one, but I want to build one for her. You know, it comes from me. Something that she can give to her kid and say your grandfather made this. [Laughs.] For building material, I used to take Josie to Home Depot. You know, let's go talk to somebody about the kind of material I should be using. So something that is maybe 4-feet tall and 3-feet wide or something that she can keep all her books, keep it in her bedroom or something, you know. . . . I saw one online, like my sister-in-law has one in their living room. I really like the way they have set it up. They have these little kids' chairs, they have those sofa chairs for kids and, um, they have it set up in their living room where they have a couple of those chairs and they have a big giant teddy bear and that's their story area. So that's where they sit down and read stories there. That's kind of what I want for Josie.

In his historical analysis, Gelber (2000) documents the emergence of do-it-yourself projects as a standard practice of suburban fatherhood. According to Gelber, the most prominent cultural rationales for DIY gave little emphasis to monetary savings. Rather, DIY functioned more as a symbolic endeavor through which men enacted the cultural myth of preindustrial artisanship. Through these enactments, men could assuage feelings of lost autonomy that accompanied industrialization and the rise of the bureaucratic workplace while simultaneously providing a gender-ideological appro- priate means for them to invest their identities in the domestic sphere.

At-home fathers rework this historical myth in relation to their particular sociocultural position and distinctive ideological conflicts. Rather than functioning as a therapeutic respite from bureaucratic control (an idea inextricably linked to the breadwinner model of masculinity), DIY practices afford these men a pleasurable sense of finite accomplishment akin to completing a project in the workplace. By posting stories and photos about their DIY projects, at-home fathers place these domestic practices into the public sphere, where they can garner status-enhancing recognition and social capital (via sharing) and further build their stocks of masculinized domestic cultural capital. For example, the blogger known as HomeDad kept his fellow at-home dads abreast of how his DIY project of building a chicken coop was progressing by uploading images as the project evolved and asking for feedback from fellow at-home fathers:

A few months ago I hauled home a ton (maybe more) of lumber from a neighbor's deck project that was torn down and rebuilt. My great plans included building a chicken coop with most of the found lumber. Coop 2.0 is going to have a solid roof and sidewalls to keep the rain off of them. It is quite an upgrade from the modified dog kennel that has served as my main coop for a couple of years. . . .

I am now about $\$ 75$ into the coop and I think it looks pretty awesome. I still have 15 more feet of wire to stretch on the sides and I need to build a gate and figure out the best latch to use. . . .

If you will please notice, I broke 2 (Two! BOTH!) hammers trying to pry out that nail. . . . Now it looks like I'll be back in the hammer hunt before I tackle the chicken coop building project.

Comment: Buy an Estwing. It will be the last hammer you buy for the rest of your life, at least, until your son steals it to build a loft in his dorm room. Family owned, made in America, one piece forged steel head and shaft. (HomeDad, August 7-12, 2011, rebeldad.com)

Through DIY practices, at-home fathers craft a tangible and enduring record of their productive capabilities and derive satisfaction from a completed, autotelic task-twin characteristics that stand in marked contrast to the transient, taken-for-granted and the "never finished" qualities of many forms of domestic labor (Strasser 1982). Like their suburban, breadwinner predecessors, at-home fathers' DIY projects serve to integrate a masculinizing ideal of artisanship (Holt and Thompson 2004) into their domestic responsibilities. For at-home fathers, however, this artisan ideal provides a symbolic means of drawing a masculinizing (and presumably legitimating) distinction to prevailing cultural conceptions of maternal solicitude.

At-home fathers' third strategy for masculinizing their domesticated cultural capital ideologically frames meal provision (and by implication provisional shopping) as a mere necessity that is secondary to their primary caregiving responsibilities and, hence, a tertiary aspect of their collective 
identity. In the manner of a self-perpetuating family myth (Hochschild 1989), our participants often use their activity dense, on-the-go style of parenting as a ready-made justification for outsourcing their cooking responsibilities to the market:

Tom: So I cook at least once or twice a week. It is pretty sad to say considering that is my thing but I am also doing taking the kids a lot of places so that is which I am just understanding in this conversation that I see stepping back, that's why I am not doing much cooking. I am not having the time. By the time I am done with the day it is 5 o'clock, it is too late to start cooking.

Interviewer: What do you have for dinner then?

Tom: We go out. I'll go get Chinese food, or sometimes we go out and eat at a nicer place and I cannot stand fast food but we do that too you know. That is I guess what we need is a cook.

While taking pride in their thrift-oriented contributions to their households, when it comes to meal preparation, athome fathers readily engage in a seemingly contradictory practice of purchasing market services to substitute for their own domestic labor. Yet this comparatively uneconomical propensity makes ideological sense given that few aspects of domesticity carry stronger feminine connotations than meal preparation and cooking from scratch (Miller 1998; Thompson 1996).

Several of our participants are enthusiastic consumers of Dream Dinners, a commercial service that allows them to assemble meals from premade dishes, which can then be stored in their freezers and taken out when needed. For others, Trader Joe's frozen entrées are staple items which they value for being good buys and healthy quick meal options. Regardless of their specific marketplace solutions, almost all the at-home fathers in our sample sought to minimize the time spent cooking using the rationale that they wanted to have time for more important and rewarding activities.

Unlike the labor-intensive, nurturing, emotionally vested cooking associated with femininity and caring motherhood (Brunsdon 2006; Miller 1998), at-home fathers construe food preparation as a necessary segue between more self-relevant activities with their children that can be outsourced (invoking an executive decision maker ideal). Whereas professional working mothers often struggle with pangs of guilt when taking time-saving short cuts to meal preparation (Moisio, Arnould, and Price 2004; Thompson 1996), at-home fathers express no such reservations, and, instead, interpret cooking as a practical problem to be efficiently solved:

Bryce: I've got pretty fast at making dinners and stuff like that. If a dinner takes more than 10 minutes it is probably something I'll not make for my son. . . . Sometimes he'll say he wants chicken nuggets and I am like where do you get chicken nuggets. I got some at Trader Joe's [laughs] oven roasted, white meat, no preservative chicken nuggets. So you know that's something I don't cook but if you can find in at Trader Joe's it is a good substitute.

Although everyday cooking carries feminine connotations, fun, leisure-oriented cooking in the public sphere, as exemplified by the family barbecue, orchestrated by dads wielding oversized cooking implements, has been culturally constructed as a masculine purview, quite distinct from motherly meal preparation (Kimmel 1997). At-home fathers use these fun-oriented, market options to construct symbolic boundaries between the real (i.e., feminine) cooking that moms do and their own masculinized way of performing this household act. In the following passage, Scott discusses how he has melded his love for fast food with his family meal-preparation responsibilities, giving rise to a hedonic and convenience-oriented approach that he directly contrasts to his wife's focus on nutrition and well-balanced diets:

I'll go there [grocery store] and I'll take my son with me or I'll ask him what kind he likes, which kind of pisses my wife off because "why do you ask them what they like before you cook for them?" I say, "I don't care what they eat; if it's something they like to eat I don't sit and look at the carbs or whatever." [Wife says], "You guys eat garbage" or "you guys are only happy when you eat out" or "why do you buy this junk for them?" I said, "that's what they like." If they were lazy and just sat on their butt and didn't do anything then maybe I'd have a little bit more concern, but they burn off everything that they eat. . . . It was always easier to feed them something simple, throw it in the microwave and give it to them than to make fresh stuff, so I didn't have to put too much effort. I still look for the easiest way, not the healthiest way but it's the easiest way.

Daniel and Eric are our only two participants who express an overt interest in cooking. In their identity narratives, grocery shopping and meal preparation are means to experience an adventuresome culinary cosmopolitanism. Eric, who dreams of eventually starting a new career in the art world, views cooking as an outlet for his creative impulses. He is constantly on the lookout for interesting recipes, subscribes to cooking magazines, and purchases high-end kitchen products such as an Oxo mango splitter and Les Creuset Dutch oven. Daniel, a former graphic designer, regards cooking as a potential future career and, more immediately, as a way to integrate cosmopolitan variety into his daily routine, as he continually experiments with Mediterranean, Asian, Middle Eastern, and fusion cuisines.

Rather than dissociating their identities from the acts of provisional shopping and cooking for the family (see Brunsdon 2006; Miller 1998) in the manner of our other participants, Eric and Daniel have, instead, embraced cooking as a means to acquire culinary capital, a particular form of cultural capital that is now widely popularized through cooking-oriented shows and television networks, plus a gamut of other foodie media. As a province of the HCC world of haute cuisine and celebrity chefs, culinary capital is readily converted into status enhancing forms of symbolic capital. For these at-home fathers, however, their cultivation of cu- 
linary capital goes beyond HCC status signaling. It reframes the domesticated act of cooking as a practice of personal enrichment and forges symbolic connections to the ideals of public/career recognition and achievement.

\section{DISCUSSION}

Pierre Bourdieu's driving theoretical agenda was to explicate the subtle ways in which the enduring influences of primary socialization, and their corresponding endowments of cultural capital, perpetuated dominant groups' status advantages over subordinate ones (Calhoun 1993). Sociologically oriented consumer research building on Bourdieu's theoretical legacy has extensively documented how consumption practices and expressions of consumer tastes reproduce status distinctions between higher and lower cultural capital consumers and has identified myriad structural forces that disadvantage LCC consumers when they attempt to gain status in social fields favored by more socioeconomically dominant class factions (Allen 2002; Bernthal, Crocket, and Rose 2005; Henry 2005; Üstüner and Holt 2007, 2010; Üstüner and Thompson 2012).

We extend and enrich this research stream by analyzing an emergent segment of consumers who, in response to shifting socioeconomic conditions, have adopted a new social role that is structurally inconsistent with their primary socialization (and endowed stocks of cultural capital) and, furthermore, that entails significant investments in subordinate forms of cultural capital. Our analysis brings to light previously undertheorized status implications that derive from consumers' acquisitions of subordinate cultural capital. In particular, we identify a domain of consumption practices - capitalizing consumption practices - that are undertaken by consumers who have made identity investments in subordinate forms of cultural capital and who are seeking to increase the conversion rates and status values of these acquisitions.

The interrelated concepts of subordinate cultural capital and capitalizing practices can illuminate new aspects of status competitions and social distinctions. As a case in point, let us consider Üstüner and Holt's (2010) comparative study of upper-class Turkish women who respectively possess higher and lower levels of cultural capital. They find that LCC elites confine their consumption and lifestyle fields to a Turkish context, only embracing global brands and products after they have been indigenized by Turkish celebrities and opinion leaders. In contrast, HCC Turkish elites' consumption practices are driven by cosmopolitan goals and their brand choices, vacation preferences, home décor, and aesthetic and fashion tastes are shaped by trends adopted by other elites in the global consumer epicenters of Western Europe and North America.

A paradoxical aspect of Üstüner and Holt's (2010) findings, however, is that the HCC faction reports a pronounced sense of insecurity in their tastes as well as frustrated status goals, owing to their dominated position in the Westernized field of global elite consumption. Conversely, the LCCs remain relatively content in their localized status games (which routinely affirm their privileged social position). In these localized fields, they can also draw identity value from invidious comparisons to their HCC counterparts, who are denounced as Western wannabes who lack proper appreciation and respect for Turkey's rich cultural heritage. Üstüner and Holt $(2010,53)$ explain this paradox by noting that HCC elites' educational and formative socialization has conditioned them to view a Westernized (cosmopolitan) lifestyle as an aspirational ideal. Accordingly, they have embarked on a lifelong quest to cultivate Westernized cultural capital and "to transform their habitus-instilled [Turkish] tastes."

Üstüner and Holt's (2010) insights can be further enriched by taking into account that globalized forms of cultural capital are the dominant form in the transnational economy whereas the parochial cultural capital, venerated by LCC Turkish elites, is the subordinate form (see Bardhi et al. 2012; Sassen 2002; Thompson and Tambyah 1999). HCC elites build their stocks of dominant cultural capital by sending their children to be educated - at least for some part of their academic careers-at respected European and North American institutions; traveling to well-known vacation spots and cultural epicenters in the West, and becoming relatively fluent in the tastes and cultural practices of Western elites. Through these acquisitions, HCC elites (and most particularly their children) are enabling themselves to more effectively compete for economic resources in the global economy and to gain membership in elite transnational networks that function as key circuits of economic and political power (Sassen 2006). In contrast, the LCC elites can be seen as engaging in capitalizing practices that aim to buttress the status value of their indigenized cultural capital. While clearly engaged in a status competition with the HCC faction, per Üstüner and Holt's (2010) account, they are also confronting pending threats posed by Turkey's steady integration into the global economy and the rapidly expanding number of global flows that are reshaping the nation's socioeconomic landscape. While HCC elites may suffer from self-doubts about how appropriately they can enact their acquisitions of dominant globalized cultural capital, they are, in the long run, better positioned to sustain their elite status in a world of transnational socioeconomic connections.

Our focus on subordinate versus dominant forms of cultural capital further illuminates some key interrelationships between sociocultural status and gendered forms of cultural capital. Bourdieu's writings have primarily dealt with issues of social class and have informed consumer research on lifestyle, habitus, taste, and consumer choice (Allen 2002; Arsel and Thompson 2011; Holt 1998). As increasingly recognized by feminist researchers, Bourdieu's social theory offers useful conceptual tools for analyzing the social performance of gender identities and the gendered status distinctions which they produce (e.g., McNay 2000; Reay 2004; Skeggs 1997). While social class differences have been the most widely noted and analyzed dimensions of social status games, consequential symbolic distinctions are also structured by gender norms and ideals (McCall 1992). From this standpoint, gender performances manifest a form of em- 
bodied cultural capital that can function as an asset or a liability in different markets (i.e., the labor market, the marriage market, educational market; Hakim 2010).

Skeggs (1997) addresses this relationship between social status and marginalized gender identities in her ethnography of young adult white working-class women living in Britain. She finds that these women tacitly understood that their socioeconomic marginalization was being perpetuated by an invidious gender distinction between bourgeois womanhood (encoding meanings of elegance, refinement, and controlled eroticism) and working-class femininity (with its connotations of coarseness, crudeness, and sexual promiscuity). Accordingly, they ardently sought to incorporate symbols of respectability into their performance of gender-via elaborate reworkings of their bodies, clothes, and homes-in hopes that these investments would generate status-enhancing symbolic value, thereby improving their career and marriage prospects.

In a parallel fashion, at-home fathers experience their marginalized gender identity as a status liability and as a source of social stigma. Whereas the women in Skeggs's (1997) ethnography were a marginalized group who made investments in dominant forms of cultural capital, the ranks of at-home fathers are largely constituted by members of a dominant social group (i.e., college educated white males) who have made identity investments in a subordinate form of cultural capital, linked to domesticity, femininity, motherhood, and economic undervaluation. To circumvent the status losses and stigmas posed by their lifestyle choices, at-home fathers attempt to legitimate a gender identity that exists in the cultural and ideological spaces between masculine breadwinner norms and feminine norms of maternal devotion.

At-home fathers' consumption practices draw moral authority from contemporary gender ideologies that encourage fathers to become more fully engaged in the emotional and social facets of parenting (and family life; Coltrane and Adams 2008). To further combat the feminizing connotations historically associated with domesticity, they also appropriate the cultural model of rebellious masculinity (Holt and Thompson 2004). Through their collective veneration of a rebel dad persona, at-home fathers portray themselves as a gender vanguard who is breaking free from the constraining mandates of breadwinner masculinity and as paving the way for other (middle-class) men to enact a more rewarding and socially redeeming model of masculinity and fatherhood.

At-home fathers' gender performances also showcase some unique relationships between gendered cultural capital and social capital. In Masculine Domination, Bourdieu (2001) discusses how Kabyle women's gendered dispositions help their families accrue economic, cultural, and social capital by displaying appropriate cultural tastes and managing and strengthening kinship ties. In her work on Italian American families, Di Leonardo (1987) similarly notes that women play a pivotal role in producing and reproducing social capital (e.g., creating bonds between men that serve to enhance their families' social position). In the case of at-home fathers, their skills at creating social capital are not directed at garnering more resources for their families per se but rather toward a broader goal of legitimating their collective identity.

Our findings also harbor implications for prior research on the myriad ways in which consumers cope with stigmatizing associations that derive from a marginalized identity position or participation in consumption activities that are deemed to be in some way deviant (Adkins and Ozanne 2005; Argo and Main 2008; Arsel and Thompson 2011; Henry and Caldwell 2006; Kozinets 2001; Muñiz and Schau 2005; Sandikci and Ger 2010). This body of work has primarily developed along two theoretical trajectories. The first highlights the passing strategies (Goffman 1986) that consumers use to hide discrediting information about their identities from public view, such as when older consumers refuse to acknowledge their eligibility for senior citizen discounts (Tepper 1994) or when low-literate consumers rely on coping strategies and compensatory heuristics to appear literate (Adkins and Ozanne 2005). The second addresses consumers who actively and publicly participate in consumption communities that are deemed, by the broader society, to deviate from the prevailing cultural norms and, hence, become subject to discrediting or stigmatizing associations (Arsel and Thompson 2011; Kates 2002; Kozinets 2001; Muñiz and Schau 2005; Sandikci and Ger 2010; Schouten and McAlexander 1995). Unlike passing strategies where consumers seek to mask their deviance from mainstream norms, these latter cases tend to be characterized by in-group valorizations of their members' divergence from mainstream sensibilities and standards, often through the appropriation of antiestablishment discourses.

At-home fathers' capitalizing practices, however, seek sociocultural legitimacy in ways that differ from both passing strategies and countercultural rebukes to mainstream standards of normalcy and acceptability. While at-home fathers challenge dominant cultural norms of breadwinner masculinity (Holt and Thompson 2004), they are not masking their identities-such as pretending to others that they are only caring for their children on their off-day from work-nor is their collective identity oriented around a goal of maintaining symbolic distinctions to the societal mainstream, as observed in punk, rave, biker, hipster, and gay subcultures (Arsel and Thompson 2011; Fox 1987; Kates 2002; Schouten and McAlexander 1995; Thornton 1996). On the contrary, at-home fathers are aggressively pursuing recognition by and acceptance from mainstream institutions, with a particular emphasis on the mass market and iconic household and family-oriented brands. Accordingly, our sample of athome fathers vigilantly watch for mass media representations and advertisements (particularly those involving national brands) that positively acknowledge their collective identity (although frequently couched in an ironic tone of "it's about time"). They interpret these intermittent moments of recognition as nascent signs that they are gaining, albeit 
slowly, normative legitimacy in the commercial marketplace.

Consumer researchers have, in recent years, shown an increasing interest in the relationships between the marketplace and the social construction of legitimacy. Kates (2004) discusses how corporate actions that are deemed as supporting the interests of the gay community led to enduring perceptions of brand legitimacy among that consumer collectivity. Humphreys (2010) details how historical confluences among political, economic, and sociocultural forces have generated legitimating representations of casino gambling that were propagated through mainstream news media. In both these cases, the analytic focus is on how marketplace resources and practices attain an aura of legitimacy among particular segments of society at large. Sandikci and Ger (2010) take a different tack in showing how marketplace institutions (e.g., retailers, fashion designers, media, and restaurants) catering to the growing ranks of middle and upper middle class tesettür women have supported this social class/ gender faction's collective project of destigmatizing Islamist veiling practices.

Unlike the case of tesettür women, at-home fathers currently do not have the critical mass needed to attract the attention of major advertisers nor do they draw cultural authority from a broader sociopolitical movement. Furthermore, they also lack legitimating ideological connections to career achievement, public-sphere recognition, and economic wherewithal that are manifest in the field of professional careers. However, at-home fathers strive to compensate for these limitations by investing in economic, social, and symbolic resources that support their collective identity goals (Sewell 1992). At-home fathers leverage operant resources (domestic skills that distinguish them from at-home moms, social networks, cultural forums) and operand resources (alternative market products, savings through thrift) toward their goal of market legitimation (Arnould, Price, and Malshe 2006). The configuration of consumers' resources toward creating preferred cultural schemas is linked to their structurally formed capacities to work in creative and innovative ways and their ability to "reinterpret and mobilize an array of resources in terms of cultural schemas other than those that initially constituted the array" (Sewell 1992, 19). At-home fathers' capitalizing consumption practices evince this kind of mobilization as they seek to recalibrate prevailing socioeconomic valuations of their subordinate cultural capital in ways that also serve their collective quest for cultural legitimacy.

\section{REFERENCES}

Adkins, Natalie Ross, and Julie L. Ozanne (2005), "The Low Literate Consumer," Journal of Consumer Research, 32 (June), 93-106.

$\rightarrow$ Allen, Douglas E. (2002), "Toward a Theory of Consumer Choice as Sociohistorically Shaped Practical Experience: The Fits Like a Glove (FLAG) Framework," Journal of Consumer Research, 28 (March), 515-32.

$\rightarrow$ Argo, Jennifer J., and Kelley J. Main (2008), "Stigma by Asso- ciation in Coupon Redemption: Looking Cheap because of Others," Journal of Consumer Research, 35 (December), 559-72.

Arnould, Eric J., Linda L. Price, and Avinash Malshe (2006), "Toward a Cultural Resource-Based Theory of the Consumer," in The Service-Dominant Logic of Marketing: Dialog, Debate, and Directions, ed. Robert F. Lusch and Stephen L. Vargo, Armonk, NY: M. E. Sharpe, 91-104.

Arsel, Zeynep, and Jonathan Bean (2012), "Taste Regimes and Market-Mediated Practice," Journal of Consumer Research, electronically published June 14, http://www.jstor.org/stable /10.1086/666595

Arsel, Zeynep, and Craig J. Thompson (2011), "Demythologizing Consumption Practices: How Consumers Protect Their FieldDependent Capital from Devaluing Marketplace Myths," Journal of Consumer Research, 37 (February), 791-806.

$\rightarrow$ Askegaard, Søren, and Jeppe Trolle Linnet (2012), "Towards an Epistemology of Consumer Culture Theory: Phenomenology and the Context of Context," Marketing Theory, 11 (4), 381-404.

$\rightarrow$ Bardhi, Fleura, and Eric J. Arnould (2005), "Thrift Shopping: Combining Utilitarian Thrift and Hedonic Treat Benefits," Journal of Consumer Behavior, 4 (4), 1-11.

$\rightarrow$ Bardhi, Fleura, Giana M. Eckhardt, and Eric J. Arnould (2012), "Liquid Relationships to Possessions," Journal of Consumer Research, 39 (October), 519-29, http://www.jstor.org/stable /10.1086/664037.

Baylies, Peter, and Jessica Toonkel (2004), The Stay-at-Home Dad Handbook, Chicago: Chicago Review Press.

$\rightarrow$ Bernthal, Matthew J., David Crockett, and Randall L. Rose (2005), "Credit Cards as Lifestyle Facilitators," Journal of Consumer Research, 32 (June), 130-45.

Boltanski, Luc, and Eve Chiapello (2005), The New Spirit of Capitalism, New York: Verso.

$\rightarrow$ Bolzendahl, Catherine I., and Daniel J. Myers (2004), "Feminist Attitudes and Support for Gender Equality: Opinion Change in Women and Men, 1974-1998," Social Forces, 83 (December), 759-90.

Bourdieu, Pierre (1977), Outline of a Theory of Practice, trans. Richard Nice, Cambridge: Cambridge University Press.

-__ (1984), Distinction: A Social Critique of the Judgment of Taste, London: Routledge \& Kegan Paul.

___ (1986), "The Forms of Capital," in Handbook of Theory: Research for the Sociology of Education, ed. John Richardson, New York: Greenwood, 241-58.

(2001), Masculine Domination, Stanford, CA: Polity Press.

Bourdieu, Pierre, and Jean-Claude Passeron (1977), Reproduction in Education, Society and Culture, London: Sage.

Bourdieu, Pierre, and Loic J. D. Wacquant (1992), An Invitation to Reflexive Sociology, Chicago: Chicago University Press.

$\rightarrow$ Braun, Michael, Noah Lewin-Epstein, Haya Stier, and Miriam K. Baumgärtner (2008), "Perceived Equity in the Gendered Division of Household Labor," Journal of Marriage and Family, 70 (December), 1145-56.

$\rightarrow$ Breen, Richard, and Lynn Prince Cooke (2005), "The Persistence of the Gendered Division of Domestic Labour," European Sociological Review, 21 (February), 43-57.

$\rightarrow$ Brescoll, Victoria L., and Eric Luis Uhlmann (2005), "Attitudes toward Traditional and Nontraditional Parents," Psychology of Women Quarterly, 29 (4), 436-45.

Brunsdon, Charlotte (2006), "The Feminist in the Kitchen: Martha, Martha and Nigella," in Feminism in Popular Culture, ed. 
Joanne Hollows and Rachel Moseley, New York: Berg, 4156.

Calhoun, Craig (1993), "Habitus, Field, and Capital: The Question of Historical Specificity," in Bourdieu: Critical Perspectives, ed. Craig Calhoun, Edward LiPuma, and Moishe Postone, Chicago: University of Chicago Press, 61-88.

$\rightarrow$ Carter, Prudence L. (2003), “'Black' Cultural Capital, Status Positioning, and Schooling Conflicts for Low-Income African American Youth," Social Problems, 50 (1), 136-55.

Casper, M. Lynne, and Suzanne M. Bianchi (2002), Continuity and Change in the American Family, Thousand Oaks, CA: Sage Publications.

Celsi, Richard L., Randall L. Rose, and Thomas W. Leigh (1993), "An Exploration of High-Risk Leisure Consumption through Skydiving," Journal of Consumer Research, 20 (June), 1-23.

Chidester, David (2005), Authentic Fakes: Religion and American Popular Culture, Berkeley: University of California Press.

Cockburn, Cynthia (1985), Machinery of Dominance: Women, Men and Technical Know-How, London: Pluto Press.

Coltrane, Scott (1996), Family Man: Fatherhood, Housework and Gender Equity, New York: Oxford University Press.

$\rightarrow$ __ (2000), "Research on Household Labor: Modeling and Measuring the Social Embeddedness of Routine Family Work," Journal of Marriage and the Family, 62 (4), 120833.

Coltrane, Scott, and Michelle Adams (2008), Gender and Families, Lanham, MD: Rowman \& Littlefield.

$\rightarrow$ Commuri, Suraj, and James W. Gentry (2005), "Resource Allocation in Households with Women as Chief Wage Earners," Journal of Consumer Research, 32 (September), 185-95.

$\rightarrow$ Connell, R. W., and James Messerschmidt (2005), "Hegemonic Masculinity: Rethinking the Concept," Gender and Society, 19 (December), 829-59.

Cowan, Ruth Schwartz (1983), More Work for Mother, New York: Basic.

Cross, Gary (2008), Men to Boys: The Making of Modern Immaturity, New York: Columbia University Press.

$\rightarrow$ Davis, Shannon N., Theodore N. Greenstein, and Jennifer P. Gerteisen Marks (2007), "Effects of Union Type on Division of Household Labor: Do Cohabiting Men Really Perform More Housework?" Journal of Family Issues, 28 (9), 1246-72.

$\rightarrow$ Dempsey, Sarah (2009), "The Increasing Technology Divide," Feminist Media Studies, 9 (March), 37-55.

Deutsch, Francine (2000), Having It All: How Equally Shared Parenting Works, Cambridge, MA: Harvard University Press.

$\rightarrow$ Di Leonardo, Micaela (1987), "The Female World of Cards and Holidays: Women, Families and the Work of Kinship," Signs, 12 (3): 440-53.

Eligür, Banu (2010), The Mobilization of Political Islam in Turkey, New York: Cambridge University Press.

Folbre, Nancy, and Jayoung Yoon (2008), "The Value of Unpaid Child Care in the United States in 2003," in How Do We Spend Our Time? Evidence from the American Time Use Survey, ed. Jean Kimmel, Kalamazoo, MI: W. E. Upjohn Institute for Employment Research, 31-56.

$\rightarrow$ Fox, Kathryn Joan (1987), "Real Punks and Pretenders: The Social Organization of a Counterculture," Journal of Contemporary Ethnography, 16 (October), 344-70.

Gelber, Steven (2000), "Do-It-Yourself: Constructing, Repairing, and Maintaining Masculinity," in The Gender and Consumer Culture Reader, ed. Jennifer Scanlon, New York: New York University Press, 70-93.

$\rightarrow$ Giele, Janet Z. (2008). "Homemaker or Career Woman: Life Course
Factors and Racial Influences among Middle Class Americans," Journal of Comparative Family Studies, 39 (3), 393-411.

Gillis, John (1996), A World of Their Own Making: Myth, Ritual, and the Quest for Family Values, New York: Basic Books.

Gimenez, Martha E. (1990), "The Dialectics of Waged and Unwaged Work: Waged Work, Domestic Labor and Household Survival in the United States," in Work without Wages: Domestic Labor and Self-Employment within Capitalism, ed. J. Collins and M. Gimenez, Albany: SUNY University Press, $25-45$.

Goffman, Erving (1986), Stigma: Notes on the Management of Spoiled Identity, New York: Touchstone.

Griswold, Robert L. (1993), Fatherhood in America: A History, New York: Basic Books.

$\rightarrow$ Gülalp, Haldun (2001), "Globalization and Political Islam: The Social Bases of Turkey's Welfare Party," International Journal of Middle East Studies, 33 (August), 433-48.

$\rightarrow$ Hakim, Catherine (2010), "Erotic Capital," European Sociological Review, 26 (5), 499-518.

$\rightarrow$ Hatfield, Elizabeth Fish (2010), "What It Means to Be a Man: Examining Hegemonic Masculinity in Two and a Half Men," Communication, Culture and Critique, 3 (4), 526-48.

Hebdige, Dick (1979), Subculture: The Meaning of Style, London: Methuen.

$\rightarrow$ Henry, Paul C. (2005), "Social Class, Market Situation, and Consumers' Metaphors of (Dis)Empowerment," Journal of Consumer Research, 31 (March), 766-78.

$\rightarrow$ Henry, Paul C., and Mary Louise Caldwell (2006), "Self-Empowerment and Consumption: Consumer Remedies for Prolonged Stigmatization," European Journal of Marketing, 40 (9-10), 1031-48.

Hochschild, Arlie (1989), The Second Shift, New York: Avon Books.

___ (2003), The Managed Heart: Commercialization of Human Feeling, Berkeley: University of California Press.

$\rightarrow$ Holt, Douglas B. (1997), "Poststructuralist Lifestyle Analysis: Analyzing the Patterning of Consumption in Postmodernity," Journal of Consumer Research, 23 (December), 326-50.

$\rightarrow$ __ (1998), "Does Cultural Capital Structure American Consumption?" Journal of Consumer Research, 25 (June), 1-25.

$\rightarrow$ _ _ (2002), "Why Do Brands Cause Trouble? A Dialectical Theory of Consumer Culture and Branding," Journal of Consumer Research, 29 (June), 70-90.

__ (2004), How Brands Become Icons: The Principles of Cultural Branding, Cambridge, MA: Harvard Business School Press.

$\rightarrow$ Holt, Douglas B., and Craig J. Thompson (2004), "Man-of-Action Heroes: The Pursuit of Heroic Masculinity in Everyday Consumption," Journal of Consumer Research, 31 (September), 425-40.

$\rightarrow$ Humphreys, Ashlee (2010), "Semiotic Structure and the Legitimation of Consumption Practices: The Case of Casino Gambling," Journal of Consumer Research, 37 (October), 490 510.

$\rightarrow$ Illouz, Eva, and Nicholas A. John (2003), "Global Habitus, Local Stratification, and Symbolic Struggles over Identity: The Case of McDonald's Israel," American Behavioral Scientist, 47 (2), 201-29.

$\rightarrow$ Jackson, Stevi (1992), "Towards a Historical Sociology of Housework: A Material Feminist Analysis," Women's Studies International Forum, 15 (2), 153-72. 
Jenkins, Henry (1992), Textual Poachers: Television Fans and Participatory Culture, New York: Routledge.

Jenkins, Henry, and John Tulloch (1995), "Beyond the Star Trek Phenomenon: Reconceptualizing the Science Fiction Audience," in Science Fiction Audiences: Watching Doctor Who and Star Trek, ed. John Tulloch and Henry Jenkins, New York: Routledge, 3-24.

$\rightarrow$ Kates, Steven M. (2002), "The Protean Quality of Subcultural Consumption: An Ethnographic Account of Gay Consumers," Journal of Consumer Research, 29 (December), 383-99.

$\rightarrow$ __ (2003), "Producing and Consuming Gendered Representations: An Interpretation of the Sydney Gay and Lesbian Mardi Gras," Consumption Markets and Culture, 6 (1), 522.

$\rightarrow$ _ _ (2004), "The Dynamics of Brand Legitimacy: An Interpretive Study in the Gay Men's Community," Journal of Consumer Research, 31 (September), 455-64.

$\rightarrow$ Kendall, Lori (2000), “'Oh No! I'm a Nerd!': Hegemonic Masculinity on an Online Forum," Gender and Society, 14 (April), 256-74.

Kimmel, Michael (1997), Manhood in America, New York: Free Press.

$\rightarrow$ Kjeldgaard, Dannie, and Søren Askegaard (2006), “The Glocalization of Youth Culture: The Global Youth Segment as Structures of Common Difference," Journal of Consumer Research, 33 (September), 231-47.

$\rightarrow$ Kozinets, Robert V. (2001), "Utopian Enterprise: Articulating the Meaning of Star Trek's Culture of Consumption," Journal of Consumer Research, 28 (June), 67-89.

—_- (2010), Netnography: Doing Ethnographic Research Online, Thousand Oaks, CA: Sage Publications.

$\rightarrow$ Lamont, Michelle, and Annette Lareau (1988), "Cultural Capital: Allusions, Gaps and Sciences," Annual Review of Sociology, 28, 167-95.

$\rightarrow$ La Rossa, Ralph (1988), "Fatherhood and Social Change," Family Relations, 37 (4), 431-57.

___ (1997), The Modernization of Fatherhood: A Social and Political History, Chicago: University of Chicago Press.

$\rightarrow$ Leach, William (1984), "Transformations in a Culture of Consumption: Women and Department Stores, 1890-1925," Journal of American History, 71 (2), 328-42.

Lin, Nan (2001), Social Capital: A Theory of Social Structure and Action, Cambridge: Cambridge University Press.

MacKinnon, Kenneth (2003), Representing Men: Maleness and Masculinity in the Media, London: Arnold.

Mallan, Kerry M. (2002). "Picturing the Male: Representations of Masculinity in Picture Books," in Ways of Being Male: Representing Masculinity in Children's Literature and Film, ed. John Stephens, New York: Routledge, 15-37.

$\rightarrow$ Mannino, Clelia, and Francine Deutsch (2007), "Changing the Division of Household Labor: A Negotiated Process between Partners," Sex Roles, 56 (March), 309-24.

Martin, Diane M., John W. Schouten, and James H. McAlexander (2006), "Claiming the Throttle: Multiple Femininities in a Hyper-Masculine Subculture," Consumption, Markets and Culture, 9 (3), 171-205.

Mathwick, Charla, Caroline Wiertz, and Ko de Ruyter (2008), "Social Capital Production in a Virtual P3 Community," Journal of Consumer Research, 34 (April), 832-49.

Matthews, Glenna (1987), Just a Housewife, New York: Oxford University Press.

McAlexander, James H., and John W. Schouten (1998), "Brandfests: Servicescapes for the Cultivation of Brand Equity," in
Servicescapes: The Concept of Place in Contemporary Markets, ed. John F. Sherry Jr., Chicago: American Marketing Association, 377-402.

McAlexander James H., John W. Schouten, and Harold F. Koenig (2002), "Building Brand Community," Journal of Marketing, 66 (January), 38-54

$\rightarrow$ McCall, Leslie (1992), "Does Gender Fit? Bourdieu, Feminism, and Conceptions of Social Order," Theory and Society, 21 (6), 837-67.

McCracken, Grant (1988), The Long Interview, Newbury Park, CA: Sage Publications.

$\rightarrow$ McNay, Lois (2000), "Agency, Anticipation and Indeterminacy in Feminist Theory," Feminist Theory, 4 (August), 139-67.

McRobbie, Angela (2000), Feminism and Youth Culture: from Jackie to Just Seventeen, New York: Routledge.

Miller, Daniel (1998), A Theory of Shopping, New York: Cornell University Press.

$\rightarrow$ Moisio, Risto, Eric J. Arnould, and Linda L. Price (2004), "Between Mothers and Markets: Constructing Family Identity through Homemade Food," Journal of Consumer Culture, 4 (3), 361-84.

$\rightarrow$ Muñiz, Albert M., and Thomas C. O'Guinn (2001), "Brand Communities," Journal of Consumer Research, 27 (March), 412-32.

$\rightarrow$ Muñiz, Albert M., and Hope Schau (2005), "Religiosity in the Abandoned Apple Newton Brand Community," Journal of Consumer Research, 31 (March), 737-47.

O'Guinn, Thomas C., and Albert M. Muñiz (2005), "Communal Consumption and the Brand," in Inside Consumption: Frontiers of Research on Consumer Motives, Goals, and Desires, ed. David Glen Mick and S. Ratneshwar, New York: Routledge, 252-72.

Petroski, David John, and Paige P. Edley (2006), "Stay-at-Home Fathers: Masculinity, Family, Work, and Gender Stereotypes," Electronic Journal of Communication, 16 (3/4), http://www .cios.org/EJCPUBLIC/016/3/01634.HTML.

Pleck, Joseph H. (1993), “Are Family Supportive Employer Policies Relevant to Men?" in Men, Work and Family, ed. Jane C. Hood, Newbury Park, CA: Sage, 217-37.

$\rightarrow$ Reay, Diane (2004), "Gendering Bourdieu's Concepts of Capitals? Emotional Capital, Women and Social Class," Sociological Review, 52 (October), 57-74.

$\rightarrow$ Rochlen, Aaron B., Ryan A. McKelley, and Tiffany A. Whittaker (2010), "Stay-at-Home Fathers' Reasons for Entering the Role and Stigma Experiences: A Preliminary Report," Psychology of Men and Masculinity, 11 (October), 279-85.

$\rightarrow$ Rochlen, Aaron B., Marie-Ann Suizzo, Ryan A. McKelley, and Vanessa Scaringi (2008), "I'm Just Providing for My Family: A Qualitative Study of Stay-at-Home Fathers," Psychology of Men and Masculinity, 9 (4), 193-206.

$\rightarrow$ Sandikci, Özlem, and Güliz Ger (2010) "Veiling in Style: How Does a Stigmatized Practice Become Fashionable?" Journal of Consumer Research, 37 (June), 15-36.

Sassen, Saskia (2002) "Cities and Communities in the Global Economy," in The City: Critical Concepts in the Social Sciences, ed. Michael Pacione, New York: Routledge, 382-292.

(2006), Territory, Authority, Rights: From Medieval to Global Assemblages, Princeton, NJ: Princeton University Press.

$\rightarrow$ Schau, Hope Jensen, Mary C. Gilly, and Mary F. Wolfinbarger (2009), "Consumer Identity Renaissance: The Resurgence of Identity-Inspired Consumption in Retirement," Journal of Consumer Research, 36 (August), 255-76. 
Schau, Hope Jensen, Albert M. Muñiz Jr., and Eric J. Arnould (2009), "How Brand Community Practices Create Value," Journal of Marketing, 73 (September), 30-51.

Schouten, James, and James McAlexander (1995), "Subcultures of Consumption: An Ethnography of New Bikers," Journal of Consumer Research, 22 (June), 43-61.

Schulz, Jeremy (2006), "Vehicle of the Self: The Social and Cultural Work of the H2 Hummer," Journal of Consumer Culture, 6 (1), 57-86.

Sewell, William F. (1992), "A Theory of Structure: Duality, Agency, and Transformation," American Journal of Sociology, 98 (July), 1-29.

Shaver, Katherine (2007), "Stay-at-Home Dads Forge New Identities, Roles," Washington Post, 17, http://www .washingtonpost.com/wpdyn/content/article/2007/06/16/ AR2007061601289.html.

Sherry, John F., Jr., Robert V. Kozinets, Adam Duhachek, Benét DeBerry-Spence, Krittinee Nuttavuthisit, and Diana Storm (2004), "Gendered Behavior in a Male Preserve: Role Playing at ESPN Zone Chicago," Journal of Consumer Psychology $14(1 / 2), 151-58$.

Skeggs, Beverley (1997), Formations of Class and Gender: Becoming Respectable, London: Sage.

Smith, Jeremy Adam (2009), The Daddy Shift: How Stay-at-Home Dads, Breadwinning Moms, and Shared Parenting Are Transforming the American Family, Boston: Beacon Press.

Sparke, Penny (1995), As Long as It Is Pink: The Sexual Politics of Taste, London: Pandora.

Strasser, Susan (1982), Never Done: A History of American Housework, New York: Pantheon.

Swartz, David (1997), Culture and Power: The Sociology of Pierre Bourdieu, Chicago: University of Chicago Press.

$\rightarrow$ Tepper, Kelly (1994), "The Role of Labeling Processes in Elderly Consumers' Responses to Age Segmentation Cues," Journal of Consumer Research, 20 (March), 503-19.

$\rightarrow$ Thompson, Craig J. (1996), "Caring Consumers: Gendered Consumption Meanings and the Juggling Lifestyle," Journal of Consumer Research, 22 (March), 388-407. $\rightarrow$ ___ (1997), "Interpreting Consumers: A Hermeneutical Framework for Deriving Marketing Insights from the Texts of Consumers' Consumption Stories," Journal of Marketing Research, 34 (November), 438-55.

$\rightarrow$ Thompson, Craig J., William B. Locander, and Howard R. Pollio (1989), "Putting Consumer Experience Back into Consumer Research: The Philosophy and Method of Existential-Phenomenology," Journal of Consumer Research, 16 (September), 133-47.

Thompson, Craig J., and Siok Kuan Tambyah (1999), “Trying to Be Cosmopolitan," Journal of Consumer Research, 26 (December), 214-41.

Thornton, Sarah (1996), Club Cultures: Music, Media, and Subcultural Capital, Middletown, CT: Wesleyan University Press.

$\rightarrow$ Üstüner, Tuba, and Douglas B. Holt (2007), "Dominated Consumer Acculturation: The Social Construction of Poor Migrant Women's Consumer Identity Projects in a Turkish Squatter," Journal of Consumer Research, 34 (June), 41-56.

$\rightarrow$ __ (2010), "Toward a Theory of Status Consumption in Less Industrialized Countries," Journal of Consumer Research, 37 (June), 37-56.

$\rightarrow$ Üstüner, Tuba, and Craig J. Thompson (2012), "How Marketplace Performances Produce Interdependent Status Games and Contested Forms of Cultural Capital," Journal of Consumer Research, 38 (February), 796-814.

Weiss, Jessica (2000), To Have and to Hold: Marriage, Baby Boom and Social Change, Chicago: University of Chicago Press.

Willis, Paul (1981), Learning to Labor: How Working Class Kids Get Working Class Jobs, New York: Columbia University Press.

Wilson, Elizabeth (2003), Adorned in Dreams: Fashion and Modernity, New Brunswick, NJ: Rutgers University Press.

Zick, Cathleen D., and W. Keith Bryant (2008), "Does Housework Continue to Narrow the Income Gap?" in How Do We Spend Our Time? Evidence from the American Time Use Survey, ed. Jean Kimmel, Kalamazoo, MI: W. E. Upjohn Institute for Employment Research, 57-80. 